\title{
The Effects of Magnetic Treatment On Seedling Growth, Nitrogen Metabolism, And Mineral Nutrient Contents In PopulusxEuramericana 'Neva' Under Cadmium Stress
}

\section{Xiumei Liu}

State Forestry and Grassland Administration Key Laboratory of Silviculture in downstream areas of the Yellow River

Fengyun Ma ( $\nabla$ sdmfy@sdau.edu.cn )

State Forestry and Grassland Administration Key Laboratory of Silviculture in downstream areas of the Yellow River Lu Wang

State Forestry and Grassland Administration Key Laboratory of Silviculture in downstream areas of the Yellow River Hong Zhu

Forestry College of Shandong Agricultural University Tai'an

\section{Shiyuan Meng}

State Forestry and Grassland Administration Key Laboratory of Silviculture in downstream areas of the Yellow River

\section{Sisheng Bi}

Shandong Academy of Forestry

\section{Jianyao Guo}

Shandong Forestry Protection and Development Center

\section{Huatian Wang}

Forestry College of Shandong Agricultural University Tai'an

\section{Research Article}

Keywords: cadmium stress, magnetization, enzyme activities, mineral nutrient, free amino acids

Posted Date: August 17th, 2021

DOI: https://doi.org/10.21203/rs.3.rs-739553/v1

License: (9) (i) This work is licensed under a Creative Commons Attribution 4.0 International License. Read Full License 


\section{Abstract}

Background: The potted experiment was carried out to investigate the mechanism of nutrient metabolism and seedling growth caused by magnetic treatment (MT) following exposure to cadmium (Cd) stress. One-year-old seedlings of Populusxeuramericana 'Neva' were treated with different $\mathrm{Cd}\left(\mathrm{NO}_{3}\right)_{2}$ solutions for 30 days. Properties of seedling growth and root morphology were promoted by MT under Cd exposure.

Results: Contents of ammonium $\left(\mathrm{NH}_{4}{ }^{+}-\mathrm{N}\right)$, nitrate $\left(\mathrm{NO}_{3}{ }^{-} \mathrm{N}\right)$, and total nitrogen $(\mathrm{TN})$ in leaves, also $\mathrm{NH}_{4}{ }^{+}-\mathrm{N}$ and TN in roots, were increased by $\mathrm{MT}$ combined with Cd-stress, although $\mathrm{NO}_{3}{ }^{-} \mathrm{N}$ content was decreased. Activities of nitrate reductase (NR), nitrite reductase (NiR), glutathione reductase (GR), and glutamate synthase (GOGAT) in leaves and activities of NR, GS and GOGAT in roots were stimulated by MT; conversely, NiR activity in roots was inhibited. MT improved the synthesis of cysteine (Cys) and glutamine (GIn) in leaves and reduced the contents of glutamic acid (Glu) and glycine (Gly), while contents of Cys, Glu, Gln, and Gly were increased in roots. (4) The contents of Ca, Mg, Fe, Mn, Zn and Cu were increased by MT under $\mathrm{Cd}$ stress in leaves, whereas content of $\mathrm{K}$ was reduced. In roots, contents of $\mathrm{K}, \mathrm{Ca}$, and Fe were increased by MT under Cd-stress, but the contents of $\mathrm{Na}, \mathrm{Mg}, \mathrm{Mn}, \mathrm{Zn}$, and Cu were decreased.

Conclusions: Magnetization could regulate the uptake of mineral nutrients by roots and translocation from the roots to aboveground parts by affecting the root morphology. MT could also improve nitrogen assimilation and the synthesis of free amino acids by stimulating the activities of key enzymes.

\section{Introduction}

Cadmium (Cd) is a widely distributed heavy metal with potential toxicity and strong mobility. Although it is easily absorbed by plants, $\mathrm{Cd}$ is a non-essential element for plant growth, and even very low concentrations can alter a variety of physiological processes in plants, affect plant growth and yield, and even influence human health through the food chain [60]. Overall, accumulation of $\mathrm{Cd}$ in plant tissues induces the production of superoxide anion $\left(\mathrm{O}^{2-}\right)$, hydrogen peroxide $\left(\mathrm{H}_{2} \mathrm{O}_{2}\right)$, and malondialdehyde (MDA), which cause oxidative stress, degrade protein and nucleic acid structures, impact the composition and fluidity of the cell membrane, and interfere with $\mathrm{H}^{+}$flux [59]. Additionally, Cd accumulation may alter the structure and function of organelles, such as chloroplasts and mitochondria, thereby suppressing photosynthesis and respiratory processes, reducing the activity of key enzymes, interfering with plant metabolism, and inhibiting plant growth and development [24]. Cd stress also affects the absorption, translocation and distribution of C, N, P, K, Ca, Mg, Fe, Mn, Zn and $\mathrm{Cu}$ [30], altering plant nutrient composition. When changes occur in the soil environment, plants actively adjust nutrient requirements to modulate element abundance. Liebig's law of the minimum states that the element with the lowest relative content has a limiting effect on plant growth. In general, nitrogen $(\mathrm{N})$ and phosphorus $(\mathrm{P})$ play important roles in plant growth, and potassium (K) and other trace elements are essential for plant metabolism and serve as key nutrients. Indeed, these elements are indispensable for the synthesis and metabolism of important macromolecules in plants, such as proteins and nucleic acids [57]. Furthermore, the $\mathrm{N}$ supply controls carbon storage [21], and $\mathrm{K}$ is an important anti-stress element for plants to adapt to adverse environments and is the most abundant ion regulating cell osmotic pressure and turgor pressure [9]. As the amino acid contents in crops and grains of different Cd-tolerant varieties may fluctuate [29], the presence of Cd can alter the ecological processes of a habitat, affect the availability of mineral nutrients and change the utilization of nutrients by plants; it also leads to a vicious cycle in which $\mathrm{Cd}$ and other nutrients simultaneously limit plant growth [12,62]. Nonetheless, results to date are inconsistent due to differences in research materials, treatment methods, and Cd concentrations, and the mechanism by which Cd stress affects plant nutrients has not yet been clarified. Overall, methods for alleviating the growth damage resulting from Cd stress in plants are of great significance.

Water can be magnetized by flowing through a magnetic static field or a magnetic device, which would change some of the physical and chemical properties of water, including optics, electromagnetism, thermodynamics and mechanics, such as changes in dielectric constant, polarity, surface tension force, conductivity, electric conductivity and dissolution of salt 
compared to pure water [52,53]. The response of biological systems to magnetic treatment of water has been reported, and both the activation of ions and polarization of dipoles in living cells are influenced by the magnetic field. Some positive results have been documented with regard to the growth and output of crops, including irrigation with low-quality water treated by a magnetic device [52]. Accordingly, magnetic treatment of water, even the low-quality water used for agro-forestry, may be feasible because it is affordable, convenient, and non-polluting to the plants, soil and environment [3].

In recent years, many studies and applications have focused on the magnetic technique in agricultural fields, including seed treatment, crop stress resistance, magnetic treatment of irrigation water, and soil quality improvement. The results indicated that such treatment could promote seed germination, enhance stress resistance, and increase crop output and quality. First, magnetized water could enhance cellular metabolism and viability, thus promoting seed germination. For example, Morejón et al. [45] used magnetized water to irrigate the seeds of Pinus tropicalis, increasing the germination rate and significantly enhancing seedling growth. Maheshwari and Grewal [41] observed that crop yield and water use efficiency in snow peas (Pisum sativum L var. macrocarpon), peas (Pisum sativum L.), and celery (Apium graveolens L.) were improved following irrigation with regenerated water and saline water after magnetic treatment. Surendran et al. [51] found that the growth of cowpea (Vigna unguiculata variety Kanakamani) and brinjal (Solanum melongena variety Haritha) and their yield increased due to irrigation with magnetized saline water, and ul-Haq et al. [55] revealed that irrigation with magnetized water not only increased the germination rate, dry and fresh weights, and chlorophyll contents of rappini seeds (Brassica rapa L.) but also increased alpha-amylase and protease activities. Second, magnetized water can increase the permeability of biological membranes, the absorption of nutrients by plants, and the resistance of crops. Grewal and Maheshwari [22] showed that the magnetic treatment enhanced the biomass of snow peas (Pisum sativum $L$ var. macrocarpon) and Cabrera chickpea (Cicer arietinum L.) by 20-25\%, and absorption of $\mathrm{N}, \mathrm{K}, \mathrm{Ca}, \mathrm{Mg}, \mathrm{S}, \mathrm{Na}, \mathrm{Zn}, \mathrm{Fe}$, and $\mathrm{Mn}$ was also promoted. Yao et al. [64] reported that damage to cucumber (Cucumis sativus) seedlings subjected to UV-B (ultra-violet-B) stress was alleviated by magnetic treatment. Finally, magnetization changes the $\mathrm{pH}$, conductivity, and hardness of water, thereby promoting the dissolution of inorganic salts. Khoshravesh et al. [33] revealed that the soil water content (7.5\%) increased following drip irrigation with magnetized water, and Khoshravesh-Miangoleh and Kiani [32] demonstrated that soil density was effectively regulated by irrigation with magnetized water, whereas the cumulative infiltration and infiltration rates were increased. In addition, Mostafazadeh-Fard et al. [44] showed that the leaching of $\mathrm{Cl}^{-}, \mathrm{HCO}_{3}{ }^{-}$, and $\mathrm{Na}^{+}$was promoted by long-term irrigation with magnetized water, which significantly reduced secondary soil salinization. In conclusion, all these results could provide a theoretical basis for application of the magnetic treatment of water for improving stress tolerance in plants and promoting ecological restoration of the soil.

Previously, few reports have focused on the responses of plants to stress conditions under magnetization and the tolerance effects of the plants to Cd stress following exposure to the magnetic field. Among the scant literature, Liu et al. [37] found that magnetized water reduced oxidative stress by increasing the activity of superoxide dismutase (SOD) and catalase (CAT) in maize (Zea mays) under $\mathrm{Cd}$ stress. Chen et al. [10] reported that the contents of $\mathrm{H}_{2} \mathrm{O}_{2}, \mathrm{O}^{2-}$, and malondialdehyde (MDA), as well as electrolyte leakage, were reduced by magnetic treatment in Mung bean (Vigna radiate) seedlings under Cd exposure due to the increased nitric oxide synthase (NOS) activity and improved photosynthetic characteristics. Overall, these studies have preliminarily demonstrated the possibility of reducing $\mathrm{Cd}$-induced damage to plants using magnetized water, thus improving seedling growth and growing conditions. Furthermore, magnetic techniques may be applied to study the ecological restoration of $\mathrm{Cd}$-contaminated soil, aiming to elevate the efficiency of $\mathrm{Cd}$ enrichment in plants. Therefore, the hybrid species Populusxeuramericana 'Neva' (Neva hereafter) was used as the experimental material in our study. We explored the possible mechanistic effects of the metabolic nutrition and biological characteristics affected by the toxicity of $\mathrm{Cd}$ in Neva underlying the influence of magnetic treatment of irrigation water to study the feasibility of cultivating a tree species of Neva in Cd-contaminated soil.

\section{Materials And Methods}

\section{Study area}


A pot experiment was carried out in the greenhouse at the Forestry Research Station of Shandong Agricultural University $\left(117^{\circ} 08^{\prime} \mathrm{E}, 36^{\circ} 11^{\prime} \mathrm{N}\right)$ from March to May in 2017 . The project involved glasshouse experiments, which were conducted with natural light, day and night temperatures of $20-25^{\circ} \mathrm{C}$, a relative humidity of $60 \%-70 \%$, and a 12-hour photoperiod at $800-1000$ $\mu \mathrm{mol}$ photons $\mathrm{m}^{-2} \mathrm{~s}^{-1}$ of photosynthetically active radiation per day of natural light throughout the study period.

\section{Plant materials}

The experimental materials consisted of one-year-old seedlings of Neva, that collecting from the seedling nursery garden. The tree nursery locates in Gaoqiao state-owed forestry farm of Ningyang country, Shandong province. In late March, the mid-stems of seedlings with a diameter of $1.52 \pm 0.11 \mathrm{~cm}$ and a length of $12.0 \mathrm{~cm}$ were cut and planted in a nutrition bag $(20 \mathrm{~cm} \times 22 \mathrm{~cm})$. The cultivation substrate was perlite, and there were two cuttings per bag. During the early stage, unified water management was performed. After germination, a modified half-strength Hoagland nutrient solution was applied to irrigate the poplar seedlings. In early April, seedlings with similar development $(15 \mathrm{~cm}$ in height with six leaves) were selected and further cultivated in half-strength modified Hoagland solution containing 0 or $100 \mu \mathrm{mol} \cdot \mathrm{L}^{-1} \mathrm{Cd}\left(\mathrm{NO}_{3}\right)_{2}$ for four weeks.

\section{Experimental design}

A magnetic treatment device supplied by Magnetic Technologies L.C.C. (Russia, United Arab Emirates branch) with a permanent magnet was used. The device (U050 mg, 0.5 inch, output 4-6 $\mathrm{m}^{3} \cdot \mathrm{hr}^{-1}$ ) supplying a magnetic induction of approximately $300 \mathrm{Gs}$ was used for treating the water.

The main irrigation strategy was initiated in early April. The potted seedlings were irrigated with half-strength Hoagland solution containing 0 and $100 \mu \mathrm{mol} \cdot \mathrm{L}^{-1} \mathrm{Cd}\left(\mathrm{NO}_{3}\right)_{2}$ solution in the presence or absence of magnetic treatment. The pots were divided into four experimental groups:

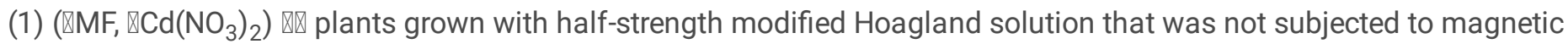
treatment $\left(\mathrm{NM}_{0}\right)$.

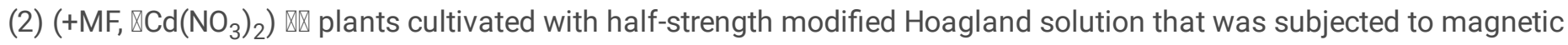
treatment $\left(\mathrm{M}_{0}\right)$.

(3) $\left(\varangle \mathrm{MF},+\mathrm{Cd}\left(\mathrm{NO}_{3}\right)_{2}\right) \otimes \square$ plants cultured with half-strength modified Hoagland solution containing $100 \mu \mathrm{mol} \cdot \mathrm{L}^{-1} \mathrm{Cd}\left(\mathrm{NO}_{3}\right)_{2}$ that was not subjected to magnetic treatment $\left(\mathrm{NM}_{100}\right)$.

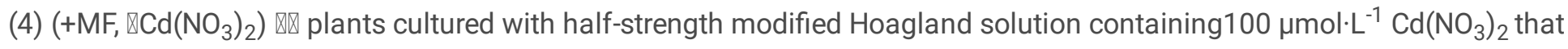
was subjected to magnetic treatment $\left(\mathrm{M}_{100}\right)$.

Half of the pots were irrigated with magnetized nutrient solution, and both groups were maintained with optimal substrate watering, with irrigation every five days. Young leaves and fine roots were collected after 30 days, rinsed with deionized water, and stored at $-80^{\circ} \mathrm{C}$ for later testing.

\section{Determination of biochemical and physiological characteristics}

\section{Growth characters analysis}

For the measurement of seedling growth, each sample was gently uprooted, carefully washed under running tap water and deionized water, and then divided into leaves and roots. The individual ground diameters of the seedlings were measured 
using Vernier calipers, and the data were recorded. The length, surface area, diameter of roots and number of root tips were determined using a root analysis system (WinRHIZO Pro 2007, Regent Instruments, Quebec, Canada). A portable leaf area meter (Cl-202; CID Bio-Science, Inc., Camas, Washington, USA) was employed to analyze the leaf area.

\section{Tissue nitrogen contents measurement}

Fine roots and leaves were rinsed with deionized water, and $0.5 \mathrm{~g}$ of fresh sample was used to determine the ammonium nitrogen $\left(\mathrm{NH}_{4}{ }^{+}-\mathrm{N}\right)$ content using the salicylic acid-sulfuric acid $\left(\mathrm{SA}-\mathrm{H}_{2} \mathrm{O}_{2}\right)$ method, as described by Zhao and Cang [66]. Afterwards, the fresh samples were dried at $80^{\circ} \mathrm{C}$ to a constant weight, and $2.0 \mathrm{~g}$ of dry leaves and roots was used to measure the nitrate nitrogen content $\left(\mathrm{NO}_{3}{ }^{-} \mathrm{N}\right)$ using the colorimetric method of $\mathrm{Xu}$ [63] based on ninhydrin. The total nitrogen (TN) content was measured using the Kjeldahl method.

\section{Tissue ion contents test}

Dried samples $(0.1 \mathrm{~g})$ were digested in a $\mathrm{H}_{2} \mathrm{SO}_{4}-\mathrm{H}_{2} \mathrm{O}_{2}$ solution, and the extract was used to determine elemental contents. The contents of K, Ca, Na, Mg, Fe, Mn, Zn and Cu were measured using an atomic absorption spectrophotometer (TU-1900, Pgeneral Ltd., Peking, China), as reported by Zhao and Cang [68].

\section{Enzyme activities determination}

The activities of nitrate reductase (NR) and nitrite reductase (NiR) were assessed in accordance with the method described by Kandeler et al. [31]. Glutamine synthetase (GS) activity was determined using hydroxylamine as a substrate, and $\mathrm{Y}^{-}$ glutamylhydroxamate ( $\mathrm{\gamma}$-GHM) formation was evaluated using acidified ferric chloride in accordance with the assay described by Loyala-Vergas and De Jimenez [39]. Glutamate synthase (GOGAT) was assessed through NADH oxidation and spectrophotometric measurement at $340 \mathrm{~nm}$, as described by Barbosa et al. [5].

\section{Amino acid contents estimating}

Fresh roots and leaves $(0.5 \mathrm{~g})$ were used to determine the contents of cysteine (Cys), glutamate (Glu), glutamine (GIn) and glycine (Gly) by high-performance liquid chromatography (HPLC)[27].

\section{Photosynthetic pigments observation}

The photosynthetic pigments chlorophyll a (Chl a), $\mathrm{Chl} \mathrm{b}$ and carotenoids (Car) in $5 \mathrm{~g}$ of fresh leaves of each sample were extracted in $5 \mathrm{ml}$ of $80 \%$ acetone, and absorbance was measured spectrophotometrically at 663,646 and $450 \mathrm{~nm}$ using a TU-1900 according to the method described by Singh et al. [50].

\section{Statistical analysis}

The results for all treatments were obtained using at least three replicates. Data were statistically analyzed with SAS software (Version 8.0; SAS Institute, Cary, NC, USA). Homogeneity of variance among means was examined using one-way analysis of variance (ANOVA) of Duncan's multiple test at the level of 0.05 .

\section{Results}

\section{Plant growth}

A comparison was performed between the roots and leaves with regard to biomass (dry weight), leaf area, and the length of fresh treetop (Fig. 1) of 'Neva' seedlings under different treatments. The results showed that in comparison to the controls $\left(M_{0}, N M_{0}\right), C d$ stress treatment $\left(M_{100}, N M_{100}\right)$ inhibited the biological characteristics of 'Neva'. Compared with the $M_{0}$ and 
$\mathrm{NM}_{0}$ treatments, the results for the $\mathrm{M}_{100}$ and $\mathrm{NM}_{100}$ treatments were as follows: leaf biomass decreased by $19.72 \%$ and $33.46 \%$ (Fig. 1A), respectively; root biomass decreased by $26.46 \%$ and $38.32 \%$ (Fig. 1B), respectively; leaf area decreased by $32.83 \%$ and $29.18 \%$ (Fig. 1C), respectively, and this difference was significant $(P<0.05)$; and new-tip length decreased by $9.64 \%$ and $9.90 \%$ (Fig. 1D), respectively, but this difference was not significant. Moreover, under the $\mathrm{NM}_{100}$ treatment, the decrease in root biomass was the most significant, followed by the decrease in leaf biomass. Additionally, comparison of the $\mathrm{NM}_{0}$ and $\mathrm{NM}_{100}$ treatments showed that the leaf biomass, roots biomass, and growth of new treetop and leaf areas in magnetized plants were all promoted under Cd stress. The change in leaf biomass under the $\mathrm{M}_{0}$ treatment was small compared with the $\mathrm{NM}_{0}$ treatment (0.39\%), and the change in leaf biomass was $21.11 \%$ higher in the $\mathrm{M}_{100}$ than the $\mathrm{NM}_{100}$ treatment, although this difference was not significant $(P>0.05)$. Between the $M_{0}$ and $N M_{0}$ treatments, the root biomass increased by $9.26 \%$ and $30.26 \%$, but this difference was not significant $(P>0.05)$; the new-tip was also significantly enhanced by $19.79 \%$ and $20.13 \%(P<0.05)$. In the $M_{100}$ treatment, the root biomass increased the most, followed by the leaf biomass. In the magnetic treatments, the leaf area of the plants increased significantly $(P<0.05)$ at rates of $33.23 \%$ and $26.37 \%$ for the $\mathrm{M}_{0}$ and $\mathrm{NM}_{0}$ treatments, respectively.

\section{Photosynthetic pigment contents}

Comparison of the $\mathrm{M}_{0}$ and $\mathrm{NM}_{0}$ treatments revealed decreases in the contents of Chl a (Fig. 2A), Chl b (Fig. 2B), and Car (Fig. 2C) under Cd stress. Specifically, compared with the $\mathrm{M}_{0}$ treatment, the contents of $\mathrm{Chl} a, \mathrm{Chl} b$ and Car in the $\mathrm{M}_{100}$ treatment decreased by $38.65 \%, 34.74 \%$, and $31.11 \%$, respectively (all $\mathrm{P}<0.05$ ), with $\mathrm{Chl}$ a showing the greatest decrease followed by

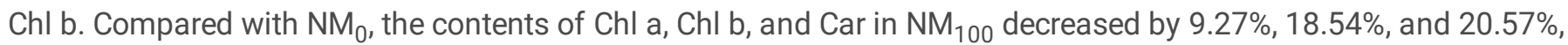
respectively (all $\mathrm{P}<0.05$ ). In a comparison of $\mathrm{NM}_{0}$ and $\mathrm{NM}_{100}$, we found that magnetic treatment stimulated the synthesis of photosynthetic pigments. Specifically, compared with $\mathrm{NM}_{0}$, the contents of $\mathrm{Chl}$ a, $\mathrm{Chl}$ b, and Car in $\mathrm{M}_{0}$ increased by $51.26 \%$, $46.25 \%$, and $35.48 \%$, respectively (all $\mathrm{P}<0.05$ ). Additionally, the photosynthetic pigment contents under $\mathrm{M}_{100}$ improved by $2.28 \%, 17.17 \%$, and $17.50 \%$ compared with $\mathrm{NM}_{100}$, respectively (all $\mathrm{P}<0.05$ ).

\section{$\mathrm{NH}_{4}{ }^{+}-\mathrm{N}, \mathrm{NO}_{3}^{-}-\mathrm{N}$ and $\mathrm{TN}$ contents}

The contents of $\mathrm{NH}_{4}{ }^{+}-\mathrm{N}$ (Fig. 3A), $\mathrm{NO}_{3}{ }^{-}-\mathrm{N}$ (Fig. 3B), and TN (Fig. 3C) were lower in leaves exposed to Cd conditions than in the control. In particular, compared with $\mathrm{M}_{0}, \mathrm{NH}_{4}{ }^{+}-\mathrm{N}, \mathrm{NO}_{3}{ }^{-} \mathrm{N}$ and $\mathrm{TN}$ contents in $\mathrm{M}_{100}$ decreased by $64.04 \%, 31.25 \%$ and $27.90 \%$, respectively, with significant differences $(\mathrm{P}<0.05)$. Moreover, $\mathrm{NH}_{4}{ }^{+}-\mathrm{N}, \mathrm{NO}_{3}{ }^{-} \mathrm{N}$ and $\mathrm{TN}$ contents in the $\mathrm{NM}_{100}$ treatment decreased by $61.32 \%, 18.41 \%$ and $25.80 \%$ compared with the values in the $\mathrm{NM}_{0}$ treatment, respectively, and these differences were significant $(\mathrm{P}<0.05)$. The content of $\mathrm{NH}_{4}{ }^{+}$showed the largest decrease, of $61.32-64.04 \%$, under $\mathrm{Cd}$ stress. Additionally, magnetic treatment was beneficial for nitrogen accumulation in leaves. Compared with $\mathrm{NM}_{0}$, the contents of $\mathrm{NH}_{4}{ }^{+}-\mathrm{N}, \mathrm{NO}_{3}{ }^{-} \mathrm{N}$ and $\mathrm{TN}$ in $\mathrm{M}_{0}$ increased by $65.08 \%, 50.49 \%$ and $7.08 \%$, respectively. Furthermore, $\mathrm{NH}_{4}{ }^{+}-\mathrm{N}, \mathrm{NO}_{3}{ }^{-}{ }^{-} \mathrm{N}$ and $\mathrm{TN}$ contents in the $\mathrm{M}_{100}$ treatment increased by $53.48 \%, 26.81 \%$ and $4.05 \%$ compared with that in the $\mathrm{NM}_{100}$ treatment, respectively, and the differences in $\mathrm{NH}_{4}{ }^{+}-\mathrm{N}$ and $\mathrm{NO}_{3}{ }^{-} \mathrm{N}$ were significant $(\mathrm{P}<0.05)$. Therefore, under magnetic treatment, the increase in $\mathrm{NH}_{4}{ }^{+}-\mathrm{N}$ was highest and ranged from 53.48 to $65.08 \%$.

However, nitrogen accumulation in roots was slightly different from that in leaves (Fig. 3). Compared with the $\mathrm{M}_{0}$ and $\mathrm{NM}_{0}$ treatments, the contents of $\mathrm{NH}_{4}{ }^{+}-\mathrm{N}_{\text {and }} \mathrm{NO}_{3}{ }^{-} \mathrm{N}$ in the $\mathrm{M}_{100}$ and $\mathrm{NM}_{100}$ treatments decreased significantly $(P<0.05)$ by $11.19 \%$ and $75.07 \%$ and $28.69 \%$ and $10.74 \%$, respectively, with $\mathrm{NH}_{4}{ }^{+}-\mathrm{N}$ showing the largest percent decrease (Fig. $3 \mathrm{~A}$ ) at an average of $43.13 \%$. These changes were opposite to what was observed for the TN content (Fig. 3C), which increased by $32.15 \%$ and $5.00 \%$ in the $M_{100}$ and $N_{100}$ treatments, respectively, with significant differences between the $M_{100}$ and $M_{0}$ treatments 
$(P<0.05)$. Compared with the $\mathrm{NM}_{0}$ and $\mathrm{NM}_{100}$ treatments, the $\mathrm{M}_{0}$ and $\mathrm{M}_{100}$ treatments caused an increase in the accumulation of $\mathrm{NH}_{4}{ }^{+}-\mathrm{N}$ and $\mathrm{TN}$ in the roots, with $\mathrm{NH}_{4}{ }^{+}-\mathrm{N}$ increasing significantly $(\mathrm{P}>0.05)$ by the largest percent.

Specifically, the $\mathrm{NH}_{4}{ }^{+}-\mathrm{N}$ content in $\mathrm{M}_{0}$ was 1.98 times higher than that in $\mathrm{NM}_{0}$, and the content in $\mathrm{M}_{100}$ was 9.62 times higher than that in $\mathrm{NM}_{100}$. The percent increases in $\mathrm{TN}$ contents in the $\mathrm{M}_{100}$ and $\mathrm{NM}_{100}$ treatments were relatively small, at $20.32 \%$ and $51.43 \%$, respectively, and this difference was significant $(\mathrm{P}<0.05)$. Compared with the changes observed in $\mathrm{NH}_{4}{ }^{+}-\mathrm{N}^{2}$ and $\mathrm{TN}$ levels, the $\mathrm{NO}_{3}{ }^{-} \mathrm{N}$ content in roots decreased under magnetic treatment (Fig. 3B), by $8.14 \%$ and $26.62 \%$ in $\mathrm{NM}_{0}$ and $\mathrm{NM}_{100}$, respectively, with the largest percent decrease observed under the $\mathrm{NM}_{100}$ treatment, which reached a remarkable level $(P<0.05)$.

\section{Activities of key enzymes in nitrogen metabolism}

Different effects on the activities of nitrogen metabolism enzymes were found in the $\mathrm{M}_{100}$ and $\mathrm{NM}_{100}$ compared with the control treatments of $\mathrm{M}_{0}$ and $\mathrm{NM}_{0}$ (Fig. 4). Cd significantly stimulated NR activity (Fig. 4A), which increased by $16.81 \%$ and $67.43 \%$ in the $\mathrm{M}_{100}$ and $\mathrm{NM}_{100}$ treatments, respectively. GS and GOGAT activities also increased in the $\mathrm{M}_{100}$ and $\mathrm{NM}_{100}$ treatments, by $9.09 \%$ and $7.23 \%$ and by $16.69 \%$ and $9.23 \%$, respectively (Fig. 4C, D), and the differences in NR and GOGAT were significant $(\mathrm{P}<0.05)$. In contrast, $\mathrm{Cd}$ stress slightly inhibited the activity of $\mathrm{NiR}$, which decreased by $3.39 \%$ and $7.61 \%$ in the $\mathrm{M}_{100}$ and $\mathrm{NM}_{100}$ treatments, respectively (Fig. $\left.4 \mathrm{~B}\right)$, though the differences were not significant $(P>0.05)$. When comparing between the $\mathrm{NM}_{0}$ and $\mathrm{NM}_{100}$ treatments, we found that the activities of nitrogen metabolism enzymes increased after magnetic treatment, with the activities of NR, NiR, GS and GOGAT all increasing by $52.47 \%, 5.58 \%, 16.69 \%$ and $19.28 \%$, respectively, between $M_{0}$ and $N_{0}$ and the differences in NR, GS and GOGAT being significant $(P<0.05)$. Compared with $\mathrm{NM}_{100}$, the activities of NR, NiR, GS and GOGAT in $\mathrm{M}_{100}$ increased by $6.38 \%, 10.39 \%, 22.55 \%$ and $27.43 \%$, respectively, and the differences in NiR, GS and GOGAT were significant $(P<0.05)$.

The nitrogen metabolism enzymes also responded differently to Cd stress (Fig. 4), which resulted in increased NR, GS and GOGAT activities (Fig. 4A, C, D). Compared with the $\mathrm{M}_{0}$ and $\mathrm{NM}_{0}$ treatments, activities under the $\mathrm{M}_{100}$ treatment increased by $36.49 \%, 32.10 \%$ and $30.55 \%$, respectively, and those under the $\mathrm{NM}_{100}$ treatment increased by $21.50 \%, 17.17 \%$ and $11.16 \%$, respectively. Cd stress had the most stimulating effect on the activity of NR, with the largest percent increase of an average of $29.00 \%$. NR and GS activities were significantly different between treatments $(P<0.05)$, and NiR activity was inhibited under Cd stress (Fig. 4B). Compared with the control treatments, NiR activity in the $\mathrm{M}_{100}$ and $\mathrm{NM}_{100}$ treatments decreased slightly by $1.00 \%$ and $5.75 \%$, respectively, but this difference was not significant $(P>0.05)$. Magnetic treatment also enhanced the activities of NR, GS, and GOGAT compared with those in seedlings without magnetic treatment. Specifically, compared with $\mathrm{NM}_{0}$, the activities of NR, GS, and GOGAT under $\mathrm{M}_{0}$ increased by $5.02 \%, 43.06 \%$ and $4.81 \%$, respectively, and the differences in GS and GOGAT activity were significant $(P<0.05)$. Furthermore, NR, GS, and GOGAT activities under $M_{100}$ increased by $17.98 \%, 61.28 \%$ and $23.10 \%$ compared with those in $\mathrm{NM}_{100}$, respectively, and the differences in NR and GS were significant $(P<0.05)$. Therefore, magnetic treatment enhanced GS activity, which showed the largest increase of an average of $52.17 \%$. However, compared with NR, GS and GOGAT, NiR activity decreased after magnetic treatment, and a comparison with the $\mathrm{NM}_{0}$ and $\mathrm{NM}_{100}$ treatments showed that NiR activity in $\mathrm{M}_{0}$ and $\mathrm{M}_{100}$ decreased by $8.80 \%$ and $4.12 \%$, respectively, though the differences were not significant $(P>0.05)$.

\section{Free amino acid contents}

Analysis of Cys, Glu, Gln, and Gly levels in leaves (Fig. 5) indicated that the contents of Cys, Gln, and Gly decreased under Cd stress compared with the controls (Fig. 5A, C, D). Overall, the contents of Cys, GIn, and Gly in the $\mathrm{M}_{100}$ treatment decreased by $24.69 \%, 34.32 \%$ and $33.89 \%$ compared with that in the $M_{0}$ treatment, respectively, and these differences were significant $(P<0.05)$. Compared with $\mathrm{NM}_{0}$, the contents of Cys, $\mathrm{Gln}$, and Gly in $\mathrm{NM}_{100}$ decreased significantly $(P<0.05)$ by $20.97 \%$, 
$32.27 \%$ and $88.46 \%$, respectively. Moreover, the percent decrease in Gly in leaves was the most significant, reaching an average of $61.18 \%$. Cd stress was beneficial for Glu synthesis (Fig. 5B), which increased by $200.05 \%$ in $M_{100}$ compared with that in $\mathrm{M}_{0}$ and increased by $4.53 \%$ in $\mathrm{NM}_{100}$ compared with that in $\mathrm{NM}_{0}$; these changes were significantly different $(P<0.05)$. $\mathrm{NM}_{0}$ and $\mathrm{NM}_{100}$ comparison indicated that magnetic treatment promoted the synthesis of Cys and GIn but inhibited that of Glu and Gly, and the differences between treatments were significant $(P<0.05)$. Compared with $\mathrm{NM}_{0}$ and $\mathrm{NM}_{100}$, the contents of Cys and GIn increased by $109.74 \%$ and $73.58 \%$ under the $M_{0}$ treatment, respectively, and by $99.88 \%$ and $11.83 \%$ under the $\mathrm{M}_{100}$ treatment, respectively. The percent content of Cys increased the most due to the magnetic treatment, by an average of $104.81 \%$. Compared with that in $\mathrm{NM}_{0}$, Glu and Gly contents in $\mathrm{M}_{0}$ decreased by $84.15 \%$ and $84.60 \%$, respectively, and compared with $\mathrm{NM}_{100}$, Glu and Gly contents in $\mathrm{M}_{100}$ decreased by $54.50 \%$ and $11.83 \%$, respectively. Gly showed the smallest percent decrease by $48.22 \%$ on average. Overall, significant differences between treatments were observed for amino acid contents $(P<0.05)$.

Different free amino acids in roots behaved differently under $\mathrm{Cd}$ stress. Compared with that in $\mathrm{M}_{0}$, contents of Cys, Glu, Gln and Gly in $\mathrm{M}_{100}$ increased significantly by $67.90 \%, 7.64 \%, 0.43 \%$ and $5.32 \%$, respectively (Fig. 5), with the largest percent increase observed for Cys and the smallest for Gln. Compared with $\mathrm{NM}_{0}, \mathrm{Cys}$, GIn and Gly contents in $\mathrm{NM}_{100}$ decreased by 9.55\%, 53.27\% and 76.53\%, respectively (Fig. 5A, C, D), and the results for Gln and Gly were significantly different $(P<0.05)$. The Glu content in $\mathrm{NM}_{100}$ was $81.06 \%$ higher than in $\mathrm{NM}_{0}$ (Fig. $\left.5 \mathrm{~B}\right)$, and these differences were significant $(P<0.05)$. Comparison of $\mathrm{NM}_{0}$ and $\mathrm{NM}_{100}$ showed an increasing trend in Cys, Glu, Gln, and Gly contents under magnetic treatment. Specifically, the increase in Cys under $\mathrm{M}_{0}$ treatment was as small as $5.95 \%$, whereas the contents of Glu, Gln, and Gly under this treatment increased dramatically and were 7.83, 3.62, and 6.22 times higher than in the $\mathrm{NM}_{0}$ treatment, respectively. The contents of Cys, Glu, Gln, and Gly in the $\mathrm{M}_{100}$ treatment were $0.97,4.25,8.94$, and 31.42 times higher than in the $\mathrm{NM}_{100}$ treatment, respectively. Additionally and remarkably, Gly showed the largest percent increase under the magnetic treatment, with an average value 18.82 times higher than under the nonmagnetic treatment. Significant differences among the four groups were found for the contents of Glu, Gln, and Gly $(P<0.05)$.

\section{Contents of the elements $\mathrm{K}, \mathrm{Ca}, \mathrm{Na}$ and $\mathrm{Mg}$}

Compared with the control treatments of $\mathrm{M}_{0}$ and $\mathrm{NM}_{0}, \mathrm{Cd}$ stress treatments exerted different effects on the four mineral elements $\mathrm{K}, \mathrm{Ca}, \mathrm{Na}$, and $\mathrm{Mg}$ in the leaves of 'Neva' (Fig. 6). In particular, $\mathrm{M}_{100}$ and $\mathrm{NM}_{100}$ induced an increase in $\mathrm{K}$ contents of $52.78 \%$ and $8.58 \%$ when comparing with $M_{0}$ and $N M_{0}$, respectively (Fig. $6 A$ ), and the $K$ contents between $M_{100}$ and $M_{0}$ were significantly different $(P<0.05)$. Compared with $M_{0}$, the Ca content in $M_{100}$ decreased by $9.93 \%$ (Fig. 6B). In contrast, the Ca content was significantly increased in $\mathrm{NM}_{100}$ compared with that in $\mathrm{NM}_{0}(\mathrm{P}<0.05)$, with a percent increase of $17.12 \%$. $M_{100}$ treatment induced an increase in Na content by $9.05 \%$ when compared with the $M_{0}$ treatment (Fig. $6 \mathrm{C}$ ), although compared with $\mathrm{NM}_{0}, \mathrm{NM}_{100}$ inhibited $\mathrm{Na}$ absorption, which decreased by $9.29 \%$; however, the differences in Na were not significant $(P>0.05)$. Cd stress had a small effect on the Mg content in leaves (Fig. 6D), which increased in the range of 0.172.86\%. Compared with $\mathrm{NM}_{0}$ and $\mathrm{NM}_{100}, \mathrm{M}_{0}$ and $\mathrm{M}_{100}$ significantly inhibited the absorption of $\mathrm{K}$ by leaves (Fig. 6A, $\left.\mathrm{P}<0.05\right)$, with decreases of $52.95 \%$ and $33.80 \%$, respectively. Conversely, these treatments benefited the accumulation of Ca and $\mathrm{Mg}$ in leaves (Fig. 6B, C), which increased by $32.33 \%$ and $0.09 \%$ in $\mathrm{M}_{0}$ compared with that in $\mathrm{NM}_{0}$, respectively, and by $1.69 \%$ and $2.86 \%$ in $\mathrm{M}_{100}$ compared with that in $\mathrm{NM}_{100}$, respectively. In addition, Ca contents in $\mathrm{M}_{100}$ and $\mathrm{M}_{0}$ showed significant differences, yet the difference in $\mathrm{Mg}$ content was not significant ( $P>0.05)$. Compared with $\mathrm{NM}_{0}$, the $\mathrm{Na}$ content in $\mathrm{M}_{0}$ decreased by $8.33 \%$ (Fig. 6D); compared with $\mathrm{NM}_{100}$, the $\mathrm{Na}$ content in $\mathrm{M}_{100}$ increased by $9.25 \%$. Significant differences were not observed between these treatments $(P>0.05)$.

A comparison of $M_{0}$ and $\mathrm{NM}_{0}$ revealed that $C d$ induced an increase in $K, C a$ and $N a$ contents in roots (Fig. 6A, B, D). Specifically, compared with $\mathrm{M}_{0}, \mathrm{~K}, \mathrm{Ca}$ and $\mathrm{Na}$ contents in $\mathrm{M}_{100}$ increased by $3.84 \%, 104.64 \%$ and $12.37 \%$, respectively, and 
compared with $\mathrm{NM}_{0}, \mathrm{~K}, \mathrm{Ca}$ and $\mathrm{Na}$ contents in $\mathrm{NM}_{100}$ increased by $2.13 \%, 49.31 \%$ and $4.17 \%$, respectively. Moreover, a significant difference in $\mathrm{Ca}$ contents between treatments was found (Fig. 6B, $\mathrm{P}<0.05$ ). In contrast, the Mg content decreased by $1.11-4.53 \%$ under $C d$ stress, but these differences were not significant (Fig. $6 \mathrm{C}, \mathrm{P}>0.05$ ). Compared with the $\mathrm{NM}_{0}$ and $\mathrm{NM}_{100}$, the $\mathrm{M}_{0}$ and $\mathrm{M}_{100}$ treatment significantly promoted absorption of $\mathrm{K}$ and $\mathrm{Ca}$ by roots, with percent increases of $17.83 \%$ and $38.75 \%$ for $M_{0}$ and $19.81 \%$ and $90.18 \%$ for $M_{100}$, respectively. The Ca content showed the greatest increase in roots, with an average of $64.47 \%$. Although the contents of $\mathrm{K}$ and $\mathrm{Ca}$ increased, $\mathrm{M}_{0}$ and $\mathrm{M}_{100}$ led to a decrease in uptake of $\mathrm{Na}$ and $\mathrm{Mg}$ by roots, with percent decreases of $11.95 \%$ and $6.87 \%$ for $M_{0}$ and $5.29 \%$ and $3.73 \%$ for $M_{100}$, respectively, although these differences were not significant $(P>0.05)$.

\section{Trace element contents}

According to the results for the four trace elements of Fe, Mn, Zn, and Cu in leaves (Fig. 7), Cd stress promoted the absorption of Fe, Mn, and Zn compared (Fig. 7A, B, C). Specifically, compared with $\mathrm{M}_{0}$, uptake of Fe, $\mathrm{Mn}$, and $\mathrm{Zn}$ in $\mathrm{M}_{100}$ increased by $9.83 \%, 7.07 \%$, and $21.04 \%$, respectively. Additionally, compared with $\mathrm{NM}_{0}$, the contents of Fe, $\mathrm{Mn}$, and $\mathrm{Zn}$ in $\mathrm{NM}_{100}$ increased by $1.03 \%, 11.52 \%$, and $5.64 \%$, respectively. The change in Fe content was markedly different between $\mathrm{M}_{0}$ and $\mathrm{M}_{100}$ (Fig. 7A, $\mathrm{P}<0.05$ ). In addition, the Cu content under $\mathrm{M}_{100}$ treatment decreased by $15.78 \%$ compared with $\mathrm{M}_{0}$ (Fig. 7D), whereas the $\mathrm{Cu}$ content in $\mathrm{NM}_{100}$ decreased by $3.65 \%$ compared with $\mathrm{NM}_{0}$; these differences were not significant $(P>0.05)$. Comparison of $\mathrm{NM}_{0}$ and $\mathrm{NM}_{100}$ revealed that magnetic treatment promoted the accumulation of Fe, $\mathrm{Mn}, \mathrm{Zn}$, and $\mathrm{Cu}$ in leaves. Notably, compared with $\mathrm{NM}_{0}, \mathrm{Fe}, \mathrm{Mn}, \mathrm{Zn}$, and $\mathrm{Cu}$ contents in $\mathrm{M}_{0}$ increased by $5.27 \%, 42.14 \%, 19.62 \%$, and $84.11 \%$, respectively, with a significant difference in Cu content between the two treatments $(P<0.05)$. Additionally, the Fe, $\mathrm{Mn}, \mathrm{Zn}$, and Cu contents in $\mathrm{M}_{100}$ increased by $14.44 \%, 36.45 \%, 37.05 \%$, and $49.59 \%$ compared with $\mathrm{NM}_{100}$, respectively, and significant differences were observed. Therefore, magnetic treatment led to the largest percent increase in Cu with an average of $66.85 \%$, followed by the percent increase in Mn with an average of $39.30 \%$.

The results indicated that $\mathrm{Cd}$ stress inhibited the accumulation of Fe and $\mathrm{Zn}$ in roots (Fig. 7A, C) under the $\mathrm{M}_{0}$ and $\mathrm{NM}_{0}$ treatments. Specifically, the contents of $\mathrm{Fe}$ and $\mathrm{Zn}$ respectively in $\mathrm{M}_{100}$ decreased by $13.16 \%$ and $32.16 \%$ compared with $\mathrm{M}_{0}$, and these contents in $\mathrm{NM}_{100}$ decreased by $34.11 \%$ and $34.09 \%$ compared with $\mathrm{NM}_{0}$. Moreover, the Zn content showed the largest percent decrease, with an average content of $33.13 \%$, and the contents of $\mathrm{Fe}$ in $\mathrm{M}_{100}$ and $\mathrm{M}_{0}$ were significantly different $(\mathrm{P}<0.05)$. In contrast, Cd stress promoted Mn uptake in leaves (Fig. 7B) and led to an improvement of $7.02 \%$ and $4.17 \%$, although the differences were not significant $(P>0.05)$. The Cu content in $M_{100}$ increased by $30.49 \%$ (Fig. 7D), whereas the Cu content in $\mathrm{NM}_{100}$ slightly decreased by $2.92 \%$, and significant differences were not observed $(P>0.05)$. Comparison of $\mathrm{NM}_{0}$ and $\mathrm{NM}_{100}$ indicated that magnetic treatment promoted the accumulation of Fe but reduced $\mathrm{Mn}, \mathrm{Zn}$, and $\mathrm{Cu}$ contents in roots. Fe contents in the $\mathrm{M}_{0}$ and $\mathrm{M}_{100}$ treatments increased by $24.91 \%$ and $64.69 \%$ compared with $\mathrm{NM}_{0}$ and $\mathrm{NM}_{100}$, respectively, but the differences between $\mathrm{M}_{100}$ and $\mathrm{NM}_{100}$ were not significant. Compared with $\mathrm{NM}_{0}$, the contents of $\mathrm{Mn}, \mathrm{Zn}$, and $\mathrm{Cu}$ in $\mathrm{M}_{0}$ decreased by $42.24 \%, 23.17 \%$, and $38.40 \%$, respectively, and these differences were significant. Finally, the contents of $\mathrm{Mn}, \mathrm{Zn}$, and $\mathrm{Cu}$ in $\mathrm{M}_{100}$ decreased by $40.66 \%, 20.93 \%$, and $20.78 \%$ compared with $\mathrm{NM}_{100}$, respectively. The Mn content decreased the most in roots, with an average of $41.45 \%$.

\section{Discussion}

Biomass is one of the most important indicators for evaluating plant resistance to stress. Cd stress in plants can affect cell division and tissue elongation by disturbing normal physiological metabolism, cell membrane functions, and related proton pump activity, thereby seriously inhibiting rootstock growth, dry matter accumulation, and even nutrient uptake and utilization [2]. This study found that $100 \mu \mathrm{mol} \cdot \mathrm{L}^{-1} \mathrm{Cd}$ stress inhibited biomass accumulation in leaves and roots of Neva, inhibited the growth of new treetop, and caused growth retardation, i.e., yellowing, crinkling, and defoliation in the blade, and 
a smaller leaf area. Our results are consistent with those of Liu et al. [38], who found that $\geq 1.0 \mathrm{~kg} \cdot \mathrm{m}^{-3} \mathrm{Cd}$ stress suppressed biomass accumulation and leaf development and caused leaf chlorosis in Glycine soja Sieb. et Zucc. Our results are also consistent with those of Lagriffoul et al. [35], who demonstrated that $25.0 \mu \mathrm{mol} \cdot \mathrm{L}^{-1} \mathrm{Cd}$ stress led to decreases in new shoot growth and leaf biomass in Zea mays L., cv. Volga. Therefore, $100 \mu \mathrm{mol} \cdot \mathrm{L}^{-1} \mathrm{Cd}$ stress might induce an inhibition of seedling growth in Neva. In addition, magnetic treatment combined with $\mathrm{Cd}$ stress significantly promoted biomass accumulation in roots and leaves, as well as stalk growth and leaf area. These results are consistent with those of Ahmad et al. [1], who found that exogenous addition of nitric oxide (NO) promoted the growth of Solanum lycopersicum L. and increased the biological yield when exposed to Cd conditions; our findings are also in accordance with those of Rahman et al. [48], who reported that the application of exogenous $\mathrm{CaCl}_{2}$ maintained a high dry weight in 29 seedlings of Oryza sativa L. cv. BRRI. The reasons for such differences in the results are as follows. The magnetization could alleviate the replaced metal elements that are essential for the metallothionein (MT) reaction center in the cells of Neva by Cd, which induced enhanced activities of lipoxygenase (LOX) and reduced activities of coenzyme II oxidase (NOX); these changes led to a lower accumulation of thiobarbituric acid reactive substances (TBARS), damaging biological macromolecules and blocking the growth and development of Neva [36]. Magnetic treatment stimulated the synthesis of photosynthetic pigments in response to Cd exposure, consistent with the results of Hasan et al. [25], who found that exogenous application of 28homobrassinolide (28-HBL) or 24-epibrassinolide (24-EBL) alleviated Cd-induced photosynthetic inhibition in tomato seedlings. Our results are also consistent with those of Christos et al. [13], who revealed that nitrogen application could alleviate chlorophyll reduction in the leaves of Zoysia japonica under $\mathrm{Cd}$ stress. Chlorophyll content is closely related to the photosynthetic rate, and magnetic treatment increases the contents of photosynthetic pigments in Neva leaves. These changes affect carbon fixation, the Hill reaction, and PSII activity in Neva leaves, resulting in enhanced photochemical quenching and enhanced stomatal conductance in leaves [8], which can accelerate the photosynthetic capacity and Cd tolerance of Neva.

Leaf characteristics reflect survival strategies formed via plant adaptation to environmental changes [4]. Under Cd stress, magnetization induced an increase in the area of Neva leaves, indicating that Neva can survive by maximizing leaf length and width, thus increasing photosynthetic production [61]. Moreover, magnetic treatment was beneficial for root morphology (Table 1) when subjected to Cd conditions, as demonstrated, for example, by improvements in indicators such as root length, surface area, diameter, volume, and number of root tips, as well as by an increase in the number of short roots $(\leq 1.5$ $\mathrm{cm}$ ). Meng et al. [43] found that different concentrations of exogenous plant growth regulators (i.e., salicylic acid (SA), jasmonic acid (JA), gibberellic acid (GA) and abscisic acid (ABA)) promoted root elongation in Brassica napus L. under Cd stress. Furthermore, Xu et al. [62] reported that exogenous application of $100 \mu \mathrm{mol} \cdot \mathrm{L}^{-1}$ sodium nitroprusside (SNP) effectively maintained plasma membrane integrity, reduced absorption of Cd by alfalfa (Medicago truncatula) seedlings, and promoted root growth. The results of the present study are similar to these findings and suggest that the limited resources could be distributed to the roots in poplar plants, thereby changing the morphological composition of its roots to adapt to the $\mathrm{Cd}$ stress environment [19]. Additionally, in poplar suffering $\mathrm{Cd}$ stress, the exchange sites in the walls of root cells to repel $\mathrm{Cd}^{2+}$ can be stimulated by the magnetization and activated coordinated expression of genes in the glutathionedependent phytochelatin (PC) synthesis pathway, thereby enhancing Cd accumulation and tolerance in roots [11] to promote root growth and development. Furthermore, improved root morphology properties are beneficial for the absorption of water and nutrients, representing an important adaptation for poplar to Cd-contained environments and suggesting that the growth mechanism induced by $\mathrm{Cd}$ is mainly responsible for the observed root activity affected by the magnetic treatment.

Nitrogen is one of the most important essential nutrients for plants. Ammonium nitrogen and nitrate nitrogen are the main forms of nitrogen absorbed from soil by plants; the latter can be directly taken up and utilized by plants, and its capacity factor reflects the velocity of nitrogen metabolism[67]. After assimilation, a portion of the nitrate is acquired by leaves, whereas the remainder is reduced to nitrite by NR in roots. Nitrite enters plastids and is reduced by NiR to ammonium, which is ultimately assimilated into amino acids and proteins [46]. Thus, the activities of NR and NiR play a very important role in the regulation of primary nitrogen assimilation. The results of our study showed that $100 \mu \mathrm{mol} \cdot \mathrm{L}^{-1} \mathrm{Cd}$ promoted the activities

Page $10 / 23$ 
of NR, GS, and GOGAT and restricted that of NiR. The effects on TN content in poplar seedlings included inhibition of TN absorption by roots and decreased TN contents in leaves. Furthermore, the changes in the NiR activity and TN content were consistent, with higher values observed in leaves than in roots. Higher leaf TN contents help to maintain leaf productivity and the maintenance of normal metabolism through the maximum carbon fixation rate [7], which is also a type of adaptation of Neva to the Cd stress environment. Otherwise, we propose that NiR may be the key rate-limiting enzyme for nitrogen transport during the growth of Neva seedlings. However, further studies are required to understand the relationship between NiR metabolism and TN. Overall, magnetic treatment induced a significant increase in nitrate nitrogen in leaves but decreased this content in roots. Moreover, magnetization induced higher NR activity in leaves and roots, and NR activity in leaves was 4-5 times greater than in roots. Consistent with the findings for nitrate nitrogen, NiR activity in leaves was enhanced and enzyme degradation was accelerated in roots; thus, leaf activity was increased more than two-fold compared with roots. The amount of ammonium nitrogen accumulated in roots was much higher than in leaves. Therefore, we conclude that the $\mathrm{NH}_{4}{ }^{+}$absorbed by roots cannot be translocated directly to leaves, which promotes preferential transport of $\mathrm{NO}_{3}{ }^{-}$from roots to leaves and leads to a decrease in $\mathrm{NO}_{3}{ }^{-}$content in the former and an increase in the latter. $\mathrm{NO}_{3}{ }^{-}$is the main effector that induces NR and NiR, and within a certain range, the activities of NR and NiR depend on the concentration of $\mathrm{NO}_{3}{ }^{-}$in the nutrient medium. Magnetization causes a sufficient supply of $\mathrm{NO}_{3}{ }^{-}$for poplar leaves, thereby promoting the activities of both NR and NiR [42]. This result is consistent with a previous finding that exogenous $\mathrm{CaCl}_{2}$ and SA administration stimulate NR activity [6]. However, magnetization resulted in higher NR and NiR activities in leaves, which increased the efficiency of nitrate reduction to nitrite and facilitated the conversion of nitrate to nitrite. In addition, the enhanced NiR activity in leaves consumed a large amount of $\mathrm{NH}_{4}{ }^{+}$, which prevented the toxicity of nitrite accumulation in leaf tissues. $\mathrm{NiR}$ in roots promoted the reduction of $\mathrm{NO}_{3}{ }^{-}$to $\mathrm{NH}_{4}{ }^{+}$and consumed an enormous amount of $\mathrm{NO}_{2}{ }^{-}$, which is the primary explanation for the decrease in NiR activity in roots. Moreover, the accumulation of $\mathrm{NH}_{4}{ }^{+}$in roots provided raw material for amino acid synthesis.

The GS-GOGAT cycle is one of the main pathways for ammonium ion assimilation, which not only relieves the toxic effects of ammonium ions on plant tissues but also helps meet the nitrogen nutrient requirements of plants [34]. GS is the key enzyme in the GS-GOGAT cycle and is involved in the regulation of various nitrogen metabolism pathways that have important effects on metabolic efficiency of the plants [58]. GS uses $\mathrm{NH}_{4}{ }^{+}$as a substrate and ATP as an energy source for amino acid synthesis and conversion, and an increase in GS activity enhances nitrogen metabolism [18]. Studies have found that Cd stress can inhibit the activity of GS and GOGAT and hence suppress the GS-GOGAT cycle efficiency, which leads to excessive $\mathrm{NH}_{4}{ }^{+}$accumulation. However, in our study, magnetization induced an increase in GS and GOGAT activities in leaves and roots and, based on the determination of total ATPase activity in cell membranes, significantly improved ATPase activity (Fig. S1 A). This finding indicates that GS induced by ATP could bind a large amount of $\mathrm{NH}_{4}{ }^{+}$to form Gln, which is then converted to two molecules of Glu by GOGAT, and the ammonium toxicity and supplementing glutamate storage can be alleviated by these transformations [16]. Moreover, magnetization induced a significant increase in the contents of Glu and GIn in root tissues, which were 3.62 to 8.93 times higher than those under nonmagnetic treatment, respectively. Glu and Gln are the main donors for nitrogen-containing organic compounds, such as amino acids, nucleic acids, chlorophyll, and polyamines, and increased Glu and Gln contents promote the synthesis of macromolecules, such as amino acids and proteins. We also found that the contents of Cys and particularly Gly synthesized in roots under magnetic treatment were approximately 18 times higher than under the nonmagnetic treatment in Neva, and these changes promoted the transport of $\mathrm{NH}_{4}{ }^{+}$from roots to leaves in the form of organic nitrogen, e.g., amino acids [47].

Under Cd stress, magnetic treatment resulted in significant increases in the contents of the four free amino acids Cys, Gln, Glu, and Gly in roots, which led to the following three findings. Primarily, by regulating amino acid metabolism in tissues, magnetization alleviated physiological damage in Neva caused by high concentrations of Cd (Fig.S2 A), such as ion homeostasis imbalances [68]. Second, amino acids inhibited HvNRT2 transcript expression in roots, and this inhibitory effect in turn blocked the synthesis of $\mathrm{NO}_{3}{ }^{-}-\mathrm{N}$ transporter mRNA, which regulates $\mathrm{NO}_{3}{ }^{-} \mathrm{N}$ uptake [56]. Finally, amino acids, which are 
reduction products of $\mathrm{NO}_{3}{ }^{-}-\mathrm{N}$, exhibited a feedback regulatory effect on nitrogen metabolism. After magnetic treatment, the significant increase in the amount of Gly synthesized in roots and the low concentration of $\mathrm{NO}_{3}{ }^{-}-\mathrm{N}^{-}$as well as the increased TN content can lead to reasonable and efficient utilization of accumulated carbohydrates, i.e., carbon skeletons, in various parts of the plant, which not only conserves energy used for $\mathrm{NO}_{3}{ }^{-} \mathrm{N}$ absorption, reduction, and the synthesis of amino acids, but it also allows 'Neva' to store additional nitrogen using only a small amount of energy [26].

When exposed to Cd conditions, the increased contents of Cys and Glu in leaves caused by the magnetic treatment provided the raw materials for protein synthesis. Under magnetization, higher GS activity increased the demand for Glu; more Glu was consumed to synthesize GIn, and a decrease in synthesized Gln was then observed. Glu exhibited a larger percent increase than did GIn, possibly because GIn has a stronger storage capacity for $\mathrm{NH}_{4}{ }^{+}$and thus plays a role in relieving the toxicity of free ammonium. Further analyses are needed to understand the magnetization-induced decrease in Gly synthesized in leaves, the relationship between Gly and other free amino acids, and their roles in nitrogen assimilation.

As a heavy metal, Cd affects the absorption and translocation of nutrients in plants, resulting in insufficiencies in nutrient elements or imbalances between nutrients and, thereby, inducing physiological disorder and inhibiting plant growth [69]. In this study, we found that $\mathrm{Cd}$ exposure promoted the absorption of $\mathrm{K}$ and $\mathrm{Mn}$ by roots and the transport of $\mathrm{K}$ and $\mathrm{Mn}$ from roots to leaves, causing an increase in $\mathrm{K}$ and $\mathrm{Mn}$ contents in leaves. However, Cd stress had less of an effect on the $\mathrm{Mg}$ content of roots and leaves, which showed no significant change. Hernández et al. [28] noted that the concentration of Cd in the medium was related to the absorption and transport of $\mathrm{K}$ by plants. Under $\mathrm{Cd}$ stress, the $\mathrm{K}$ concentration in roots increased with the accumulation of $\mathrm{Cd}$ and was higher than that in leaves, possibly due to some interaction between $\mathrm{Cd}$ and $\mathrm{K}$ in Neva roots [17]. Additionally, magnetization enhanced ATPase activity in cell membranes (Fig. S1 A), thus providing an explanation for the increase in $\mathrm{K}$ uptake. Under magnetization, the $\mathrm{K}$ content in roots increased with improving Cd content (Fig. S2 A), and the translocation of $\mathrm{K}$ to aboveground parts decreased with an increasing biological transfer coefficient of Cd (Fig. S2 B). These results suggest that magnetic treatment stimulated the binding of excess Cd with ATP in roots, resulting in less available energy for the transmembrane transport system and thus reducing $\mathrm{K}$ uptake by aboveground parts of Neva [17]. Cd stress also promoted the accumulation of Mn in leaves. González et al. [20] found that excess Mn mainly damages the aboveground parts of plants, inducing the formation of leaf brown spots, chlorosis, and leaf shrinkage. We postulate that this phenomenon may be due to the Cd-induced rapid transport of Mn in plants [14], which also explains the observation of leaf chlorosis and shrinkage during Neva growth.

After addition of exogenous $\mathrm{Cd}$, $\mathrm{Ca}$ and $\mathrm{Na}$ were absorbed by the roots of $\mathrm{Neva}$, and the contents of $\mathrm{Ca}$, $\mathrm{Na}$, and $\mathrm{Cu}$ in leaves were greater than in roots. $\mathrm{Ca}^{2+}$ and $\mathrm{Cd}^{2+}$ have similar ionic radii and can be taken up by poplar roots simultaneously through a competitive relationship. Increased contents of $\mathrm{Ca}$ in leaves is the main reason for the prevention of Cd transfer from roots to the aboveground parts of Neva, thereby leading to $\mathrm{Cd}$ accumulation in roots. This finding was confirmed by Tripathi et al. (1995)[54], who found that the presence of $\mathrm{Ca}^{2+}$ suppressed the uptake of $\mathrm{Cd}^{2+}$. After Cd stress, magnetization enhanced the ability of roots to internalize $\mathrm{Ca}$ and transfer it to leaves, leading to an increase in Ca in leaves. Changes in the leaf $\mathrm{Ca}$ concentration promote $\mathrm{Ca}^{2+}$ transporter regulation of the Ca concentration in Neva cells, inducing the initiation of calcium signaling [12] to activate calcium-dependent protein kinase (CDPK)-like proteins [23], which respond to the signal transduction generated by Cd stress and participate in the regulation of growth and development in Neva.

When subjected to $\mathrm{Cd}$ conditions, the magnetic treatment could alleviate the substitution effect of $\mathrm{Cd}^{2+}$ for $\mathrm{Fe}^{2+}, \mathrm{Zn}^{2+}$, and $\mathrm{Mg}^{2+}$ by regulating the absorption and transport of $\mathrm{Fe}, \mathrm{Zn}$, and $\mathrm{Mg}$ in roots and leaves. $\mathrm{Cd}$ and $\mathrm{Zn}$ have similar extranuclear electron configurations and can be substituted for each other. The improvement in Zn content in poplar leaves reduced the damage caused by the inactivation of chlorophyll due to compositional changes in the central ion of chlorophyll, demonstrating the adaptation of poplar to Cd conditions. Moreover, this study showed that magnetization promoted the development of root morphology in Neva, which is an important basis for improving the absorption and accumulation of Fe in roots. Constitutive co-expression of FIT and $b H L H$ genes can effectively induce the expression of IRT and FRO2 to regulate

Page 12/23 
Fe contents in aboveground plant parts [65] and to avoid the accumulation of a large amount of Fe in the root cell cytoplasm, which would lead to iron poisoning. All the biochemical reactions involving Fe are completed in the chloroplast, which contains the largest iron pool in plant cells. After magnetic treatment, both the leaf Fe and $\mathrm{Mg}$ and $\mathrm{K}$ contents increased, which promoted maintenance of the chloroplast structure and the number of thylakoids, photosynthetic electron transfer in chloroplasts, and alleviation of photochemical damage caused by $\mathrm{Cd}$ stress [15]. Magnetization also stimulated the uptake of $\mathrm{Mn}, \mathrm{Zn}$, and $\mathrm{Cu}$ by poplar roots, promoted $\mathrm{Mn}, \mathrm{Zn}$, and $\mathrm{Cu}$ transport to aboveground parts, and enhanced the contents of these elements in leaves. These effects could reduce the substitution of $\mathrm{Cd}$ for the metal elements in the reaction center and generate the production of the heavy metal-binding protein $\mathrm{Cu} / \mathrm{Zn}$-SOD in poplar cells. Excessive heavy metal Cd can increase the activity of $\mathrm{Cu} / \mathrm{Zn}-\mathrm{SOD}$, which in turn eliminates superoxide anions in plants and reduces reactive species (ROS) accumulation [49], thus maintaining the normal permeability and stability of 'Neva' cells. K and Na contents are important indicators of the ion balance and symptoms of ion damage in plant cells [40]. With magnetic treatment after addition of exogenous $\mathrm{Cd}$, the $\mathrm{Na}$ content generally decreased, and the $\mathrm{K} / \mathrm{Na}$ ratio was reduced in leaves and increased in roots (Fig. S1 B). These findings indicate that Cd stress plays a certain role in the ability of leaves to regulate the ion balance influenced by magnetization, thereby further affecting leaf-mediated ion regulation in the whole plant.

\section{Conclusion}

The results of our study indicated that magnetization could induce an improvement in seedling growth and accelerate the synthesis of photosynthetic pigments of Neva under Cd stress at a concentration of $100 \mu \mathrm{mol} \cdot \mathrm{L}^{-1}$. Additionally, it could contribute to root development. The tolerance against Cd stimulated the activity of NR and NiR in leaves, which seemed to reduce the toxicity of nitrite; otherwise, the accumulation of $\mathrm{NH}_{4}{ }^{+}$in roots could supply abundant raw materials for the synthesis of amino acids induced by irrigation with magnetic treatment of water. The enhancement of the GS-GOGAT cycle could promote the efficiency of nitrogen metabolism due to the stimulated activities of GS and GOGAT due to magnetization. The magnetization treatment could regulate the absorption and distribution of mineral nutrients in leaves and roots of Neva seedlings during exposure to Cd stress, and the enhanced concentration of ions, i.e., Ca, Fe, and K, could be helpful in improving adaptability to a Cd-contaminated environment.

\section{Declarations}

\section{Abbreviations}

All the abrreviations were indicated in the manuscripts.

\section{Ethics approval and consent to participate}

Not applicable.

\section{Consent for publication}

Not applicable.

\section{Availability of data and materials}

All data generated or analysed during this study are included in this published article [and its supplementary information files].

\section{Competing interests}

The authors declare that they have no competing interests.

\section{Funding}


The fundings were provided by the Funds for Agricultural Science and Technology of Shandong Province (Forestry Technological Innovation Project, 2009LY004), the Agricultural Major Application Technology Innovation Program of Shandong Province (Financial and Agricultural Indicators, 2016, No. 36) and the National Program of the International Introduction of Advanced Science and Technology in Forestry of China (948 Program, Grant No. 2011-4-60).

\section{Authors' contributions}

XML, FYM and HTW conceived and designed the study. LW, HZ, SSB, JYG and SYM performed the experiments. XML, FYM, $\mathrm{HZ}$ and LW analyzed the data. XML, LW and FYM wrote the manuscript. XML, FYM, LW share the first authorship. Moreover, all authors have read and approved the final manuscript.

\section{Acknowledgements}

Not applicable.

\section{References}

1. Ahmad P, Ahanger MA, Alyemeni MN, Wijaya L, Alam P. Exogenous application of nitric oxide modulates osmolyte metabolism, antioxidants, enzymes of ascorbate-glutathione cycle and promotes growth under cadmium stress in tomato. Protoplasma. 2018; 255:79-93.

2. Ahmad P, Abdel LAA, Hashem A, Abd AEF, Gucel S, Tran LSP. Nitric oxide mitigates salt stress by regulating levels of osmolytes and antioxidant enzymes in chickpea. Front Plant Sci. 2016; 7:347.

3. Aguilar CH, Dominguez-Pacheco A, Carballo AC, Cruz-Orea A, Ivanov R, Bonilla JLL. Alternating magnetic field irradiation effects on three genotype maize seed field performance. Acta Agrophys. 2009; 14:7-17.

4. Bao L, Liu Y. Comparison of leaf functional traits in different forest communities in Mt. Dongling of Beijing. Acta Ecologica Sinica. 2009; 29(7):3692-3703.

5. Barbosa JM, Singh NK, Cherry JH, Locy RD. Nitrate uptake and utilization is modulated by exogenous gammaaminobutyric acid in Arabidopsis thaliana seedlings. Plant Physiol Biochem. 2010; 48:443-450.

6. Bergareche C, Ayuso R, Masgran C, Simon E. Nitrate reductase in cotyledon of cucumber seedlings as affected by nitrate, phytochrome and calcium. Physiol Plant.1994; 91:257-262.

7. Broadley MR, Escobar-Gutiérrez AJ, Burns A. What are the effects of nitrogen deficiency on growth components of lettuce? New Phytol. 2000; 147:519-526.

8. Ci DW, Jiang D, Wollenweber B, Dai TB, Cao WX. Cadmium stress in wheat seedlings: growth, cadmium accumulation and photosynthesis. Acta Physiol Plant. 2010; 32(2):365-373.

9. Cakmak I. The role of potassium in alleviating detrimental effects of abiotic stresses in plants. J Plant Nutr Soil Sc. $2005 ; 168: 521-530$.

10. Chen YP, Li R, He JM. Magnetic field can alleviate toxicological effect induced by cadmium in mungbean seedlings. Ecotoxicology. 2011; 20:760-9.

11. Chen J, Yang LB, Gu J, Bai X, Ren Y, Fan T, Han Y, Jiang L, Xiao F, Liu Y, Cao S. MAN3 gene regulates cadmium tolerance through the glutathione-dependent pathway in Arabidopsis thaliana. New Phytol. 2015; 205:570-82.

12. Chinnusamy V, Schumaker K, Zhu JK. Molecular genetic perspectives on cross-talk and specificity in abiotic stress signaling in plants. J Exp Bot. 2004; 55:225-236.

13. Christos AD, Christos S. Safflower yield, chlorophyll content, photosynthesis and water use efficiency response to nitrogen fertilization under rained conditions. Ind Crop Prod. 2007; 27:75-85.

14. Dučić T, Polle A. Transport and detoxification of manganese and copper in plants. Braz. J Plant Physiol. 2005; 17(1):103-112. 
15. Duy D, Wanner G, Meda AR, von-Wirén N, Soll J, Philippar K. PIC1, an ancient permease in Arabidopsis chloroplasts, mediates iron transport. Plant Cell. 2007; 19(3):986-1006.

16. Ewa GE, Maria SM. Nickel-induced changes in nitrogen metabolism in wheat shoots. J Plant Physiol. 2009; 166:10341044.

17. Ghnaya T, Nouairi I, Slama I, Messedi D, Grignon C, Abdelly C, Ghorbel MH. Cadmium effects on growth and mineral nutrition of two halophytes: Sesuvium portulacastrum and Mesembryanthemum crystallinum. J Plant Physiol. 2005; 162:1133-1140.

18. Giagnonia L, Pastorelli R, Mocali S, Arenella M, Nannipieri P, Renella G. Availability of different nitrogen forms changes the microbial communities and enzyme activities in the rhizosphere of maize lines with different nitrogen use efficiency. Soil Ecology. 2016; 98:30-8.

19. Gonzaga MIS, Santos JAG, Ma LQ. Phytoextraction by arsenic hyperaccumulator Pteris vittata L. from six arseniccontaminated soils: Repeated harvests and arsenic redistribution. Environ Pollut. 2008; 4:212-8.

20. González A, Steffen KL, Lynch JP. Light and excess manganese 1: Implication for oxidative stress in common bean. Plant Physiol. 1998; 93-504.

21. Güsewell S. N:P ratios in terrestrial plants: variation and functional significance. New Phytol. 2004; 164:243-266.

22. Grewal HS, Maheshwari BL. Magnetic treatment of irrigation water and snow pea and chickpea seeds enhances early growth and nutrient contents of seedlings. Bioelectromagnetics. 2015; 32(1):58-65.

23. Harmon AC, Gribskov M, Gubrium E, Harper JF. The CDPK superfamily of protein kinases. New Phytol. 2001; 151:58595867.

24. Hasan SA, Fariduddin Q, Ali B, Hayat S, Ahmad A. Cadmium: toxicity and tolerance in plants. J Environ Biology. 2009; 30(2):165-174.

25. Hasan SA, Hayat S, Ahmad A. Brassinosteroids protect photosynthetic machinery against the cadmium induced oxidative stress in two tomato cultivars. Chemosphere. 2011; 84(10):1446-1451.

26. Hawkesford M, Horst W, Kichry T, Lambers H, Schjoerring J, Skrumsager M, White P. Functions of macronutrients[M]//Marschner P. Marschner's mineral nutrition of higher plants. Waltham: Academic Press. 2011; 135151.

27. He Y, Chen YF, Zhu YP, Lu J, Lin RC. HPLC determination of the main free amino acids in the root of Isatis indigotica fort. Chinese Journal of Pharmaceutical Analysis. 2005; 25(3):274-7.

28. Hernández LE, Gárate A, Carpena-Ruiz R. Effects of cadmium on the uptake, distribution and assimilation of nitrate in Pisum sativum. Plant and Soil. 1997; 189(1):97-106.

29. Hsu YT, Kao CH. Changes in protein and amino acid contents in two cultivars of rice seedlings with different apparent tolerance to cadmium. Plant Growth Regul. 2003; 40:147-155.

30. Hsu YT, Kao CH. Toxicity in leaves of rice exposed to cadmium is due to hydrogen peroxide accumulation. Plant and Soil. 2007; 298 (1/2):231-241.

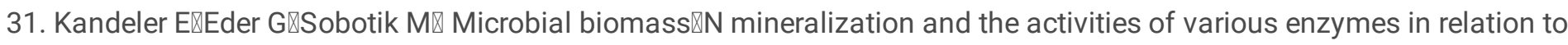

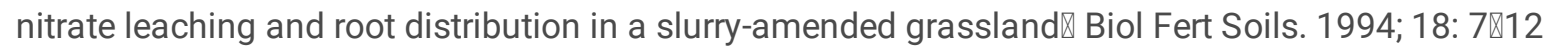

32. Khoshravesh-Miangoleh M, Kiani AR. Effect of magnetized water on infiltration capacity of different soil texture. Soil Use Manage. 2014; 30(4):588-594.

33. Khoshravesh M, Mostafazadeh-Fard B, Mousavi SF, Kiani AR. Effects of magnetized water on the distribution pattern of soil water with respect to time in trickle irrigation. Soil Use Manage. 2011; 27:515-522.

34. Kronzucker HJ, Britto DT, Davenport RJ, Tester M. Ammonium toxicity and the real cost of transport. Trends Plant Sci. $2001 ; 6(8): 335-7$.

35. Lagriffoul A, Mocquot B, Mench M, Vangronsveld J. Cadmium toxicity effects on growth, mineral and chlorophyll contents, and activities of stress related enzymes in young maize plants (Zea mays L.). Plant and Soil. 1998; 200:241- 
250.

36. Liu SL, Pan YZ, Yang RJ, Ding JJ, He Y, Wang L, Ma DM. Effects of exogenous NO on mineral nutrition absorption, lipid peroxidation and ATPase of plasma membrane in Catharanthus roseus tissues under cadmium stress. Plant Nutrition Fertilizer Sci. 2014; 20(2):445-458.

37. Liu X, Zhang T, Huang X, Hou Y, Huang H. Magnetic water improve the tolerance of corn to Cd ion. J Xiamen University (Natural Science). 2008; 47 suppl 2:278-281.

38. Liu L, Shang YK, Li L, Chen Y.H, Qin ZZ, Zhou LJ, Yuan M, Ding CB, Liu J, Huang Y, Yang RW, Zhou YH, Liao JQ. Cadmium stress in Dongying wild soybean seedlings: growth, $\mathrm{Cd}$ accumulation, and photosynthesis. Photosynthetica. 2018; 56(4):1346-1352.

39. Loyala-Vergas and De Jimenez, Estela SDJ. Differential role of glutamate dehydrogenase in nitrogen metabolism of Maize tissues. Plant Physiology. 1984; 76(2):536-540.

40. Maathuis FJM, Amtmann A. $\mathrm{K}^{+}$nutrition and $\mathrm{Na}^{+}$toxicity: The basis of cellular $\mathrm{K}^{+} / \mathrm{Na}^{+}$ratios. Ann Bot-london. 1999 ; 84:123-133.

41. Maheshwari BL, Grewal HS. Magnetic treatment of irrigation water: Its effects on vegetable crop yield and water productivity. Agr Water Manage. 2009; 96:1229-1236.

42. Malagoli M, Dal Cannal A, Quaggiotti S, Pegoraro P, Bottacin A. Differences in nitrate and ammonium uptake between Scots pine and European larch. Plant Soil. 2000; 221:1-3.

43. Meng HB, Hua SJ, Shamsi IH, Jilani G, Li YL, Jiang LX. Cadmium-induced stress on the seed germination and seedling growth of Brassica napus L., and its alleviation through exogenous plant growth regulators. Plant Growth Regul. 2009; 58:47-59.

44. Mostafazadeh-Fard B, Khoshravesh M, Mousavi SF, Kiani AR. Effects of magnetized water on soil chemical components underneath trickle irrigation. J Irrig Drain Eng. 2012; 138(12):1075-1081.

45. Morejón LP, Castro Palacio JC, Velázquez Abad L, Govea A.P. Stimulation of Pinus tropicalis M. seeds by magnetically treated water. Int. Agrophysics. 2007; 21:173-7.

46. Nacry P, Bouguyon E, Gojon A. Nitrogen acquisition by roots: physiological and developmental mechanisms ensuring plant adaptation to a fluctuating resource. Plant Soil. 2013; 370: 1-29.

47. People M, Gifford RM. Regulation of the transport of nitrogen and carbonin higher plants||Dennis DT, Turpin DH, Lefebvre DD. (Eds.), Plant Metabolism. Longman Singapore Publishers (Pte) Ltd., London, UK, 1997; 525-537

48. Rahman A, Mostofa MG, Nahar K, Hasanuzzaman M, Fujita M. Exogenous calcium alleviates cadmium-induced oxidative stress in rice (Oryza sativa L.) seedlings by regulating the antioxidant defense and glyoxalase systems. Braz $\mathrm{J}$ Bot. 2016; 39(2):393-407.

49. Schellingen K, Van Der Straeten D, Remans T, Remans T, Vangronsveld J, Keunen E, Cuypers A. Ethylene signalling is mediating the early cadmium induced oxidative challenge in Arabidopsis thaliana. Plant Sci. 2015; 239:137-146.

50. Singh M, Singh VP, Prasad SM. Nitrogen modifies NaCl toxicity in eggplant seedlings: Assessment of chlorophylla fluorescence, antioxidative response and proline metabolism. Biocatal Agr Biotech. 2016; 7:76-86.

51. Surendran U, Sandeep O, Joseph EJ. The impacts of magnetic treatment of irrigation water on plant, water and soil characteristics. AgrWater Manage. 2016; 178:21-9.

52. Teixeira da Silva JA, Dobránszki J. Impact of magnetic water on plant growth. Environ Exp Biol. 2014; 12:137-142.

53. Teixeira da Silva JA, Dobránszki J. Magnetic fields: how is plant growth and development impacted? Protoplasma. $2016 ; 253: 231-248$.

54. Tripathi RD, Rail UN, Gupta M, Yunus M, Chandra P. Cadmium transport in submerged macrophyte Ceratophyllum demersum $\mathrm{L}$. in presence of various metabolic inhibitors and calcium channel blockers. Chemosphere. 1995; 31(7):3783-3791. 
55. ul-Haq Z, lqbal M, Jamil Y, Anwar H, Younis A, Arif M, Fareed MZ, Hussain F. Magnetically treated water irrigation effect on turnip seed germination, seedling growth and enzymatic activities. Information Proc Agr. 2016; 3:99-106.

56. Vidmar JJ, Zhuo D, Siddiqi YM, Schjoerring JK, Touraine B, Glass AD. Regulation of high-affinity nitrate transporter genes and high-affinity nitrate influence by nitrogen pools in roots of barley. Plant Physiol. 2000; 123(1):307-318.

57. Vitousek PM, Porder S, Houlton BZ, Chadwick OA. Terrestrial phosphorus limitation: mechanisms, implications and nitrogen phosphorus interactions. Ecol Appl. 2012; 20(1):5-15.

58. Wani AS, Tahir I, Ahmad SS, Dar RA, Nisar S. Efficacy of 24-epibrassinolide in improving the nitrogen metabolism and antioxidant system in chickpea cultivars under cadmium and/or $\mathrm{NaCl}$ stress. Sci Hortic-amsterdam. 2017; 225:48-55.

59. Wang QH, Liang X, Dong YJ, Xu LL, Zhang XW, Hou J, Fan ZY. Effects of exogenous nitric oxide on cadmium toxicity,element contents and antioxidative system in perennial ryegrass $\$ Plant Growth Regul. 2013; 69:11-20.

60. Wu FZ, Yang WQ, Zhang J, Zhou LQ. Cadmium accumulation and growth responses of a poplar (Populus deltoidsx Populus nigra) in cadmium contaminated purple soil and alluvial soil. J Hazard Mater. 2009; 177:268-273.

61. Wu F, Yang W, Zhang J, Zhou L. Effects of cadmium stress on growth and nutrient accumulation, distribution and utilization in Osmanthus fragrans var. thunbergii. Chinese J Plant Ecol. 2010; 34(10):1220-6.

62. Xu J, Wang WY, Yin HX, Liu XJ, Sun H, Mi Q. Exogenous nitric oxide improves antioxidative capacity and reduces auxin degradation in roots of Medicago truncatula seedlings under cadmium stress. Plant Soil. 2010; 326:321-330.

63. Xu WA. Comprehensive experimental guidance of biology. Suzhou: Soochow University Press. 2010.

64. Yao YN, Li Y, Yang YQ, Li CY. Effect of seed pretreatment by magnetic field on the sensitivity of cucumber (Cucumber sativus) seedlings to ultraviolent-B radition. Environ Exp Bot. 2004; 54(3):286-294.

65. Yuan Y, Wu H, Wang N, Li J, Zhao W, Du J, Wang D, Ling HQ. FIT interacts with AtbHLH38 and AtbHLH39 in regulating iron uptake gene expression for iron homeostasis in Arabidopsis. Cell Res. 2008; 18:385-397.

66. Zhao SJ, Cang J. Experimental guidance for plant physiology. Peking: China Agriculture Press. 2016.

67. Zhao N, Sun Y, Wang D, Zhen J. Effects of exogenous melatonin on nitrogen metabolism in cucumber seedlings under high temperature stress. Plant Phy J. 2012; 48(6):557-564.

68. Zhang P, Fu J, Hu L. Effects of alkali stress on growth, free amino acids and carbohydrates metabolism in Kentucky bluegrass (Poa pratensis). Ecotoxicology. 2012; 21(7):1911-8.

69. Zhang GP, Fukami M, Sekimoto $\mathrm{H}$. Influence of cadmium on mineral concentrations and yield components in wheat genotypes differing in Cd tolerance at seedling stage. Field Crop Res. 2002; 77:93-8.

\section{Tables}

Table 1 Changes in root morphological characteristics of 'Neva' irrigated with or without magnetized water and exposed to cadmium stress. Different lowercase letters indicate significant differences among the four treatments at the 0.05 level. Data in the table are the means \pm SD of at least three replicates.

\begin{tabular}{lllllll} 
Treatments & Length $(\mathrm{cm})$ & $\begin{array}{l}\text { Surface Area } \\
\left(\mathrm{cm}^{2}\right)\end{array}$ & $\begin{array}{l}\text { Average } \\
\text { Diameter } \\
(\mathrm{mm})\end{array}$ & $\begin{array}{l}\text { Root } \\
\text { Volume } \\
\left(\mathrm{cm}^{3}\right)\end{array}$ & Tips & $\begin{array}{l}\text { Number of } \\
\text { Short Roots } \\
\leq 1.5 \mathrm{~cm}\end{array}$ \\
\hline $\mathrm{M}_{0}$ & $260.30 \pm 18.23 \mathrm{a}$ & $71.57 \pm 5.47 \mathrm{a}$ & $0.90 \pm 0.08 \mathrm{a}$ & $1.71 \pm 0.042 \mathrm{a}$ & $1794.83 \pm 60.29 \mathrm{a}$ & $254.56 \pm 17.44 \mathrm{ab}$ \\
\hline $\mathrm{NM}_{0}$ & $152.85 \pm 31.38 \mathrm{~b}$ & $36.29 \pm 1.10 \mathrm{~b}$ & $0.64 \pm 0.18 \mathrm{a}$ & $0.74 \pm 0.038 \mathrm{a}$ & $948.67 \pm 43.31 \mathrm{c}$ & $154.41 \pm 12.12 \mathrm{c}$ \\
\hline $\mathrm{M}_{100}$ & $218.80 \pm 25.30 \mathrm{ab}$ & $52.16 \pm 15.89 \mathrm{ab}$ & $0.68 \pm 0.09 \mathrm{a}$ & $0.94 \pm 0.038 \mathrm{a}$ & $1463.17 \pm 28.27 \mathrm{~b}$ & $302.39 \pm 20.42 \mathrm{a}$ \\
\hline $\mathrm{NM}_{100}$ & $155.37 \pm 19.15 \mathrm{~b}$ & $38.58 \pm 12.19 \mathrm{ab}$ & $0.57 \pm 0.05 \mathrm{a}$ & $0.79 \pm 0.031 \mathrm{a}$ & $790.00 \pm 40.75 \mathrm{c}$ & $217.57 \pm 20.43 \mathrm{~b}$
\end{tabular}


Figures
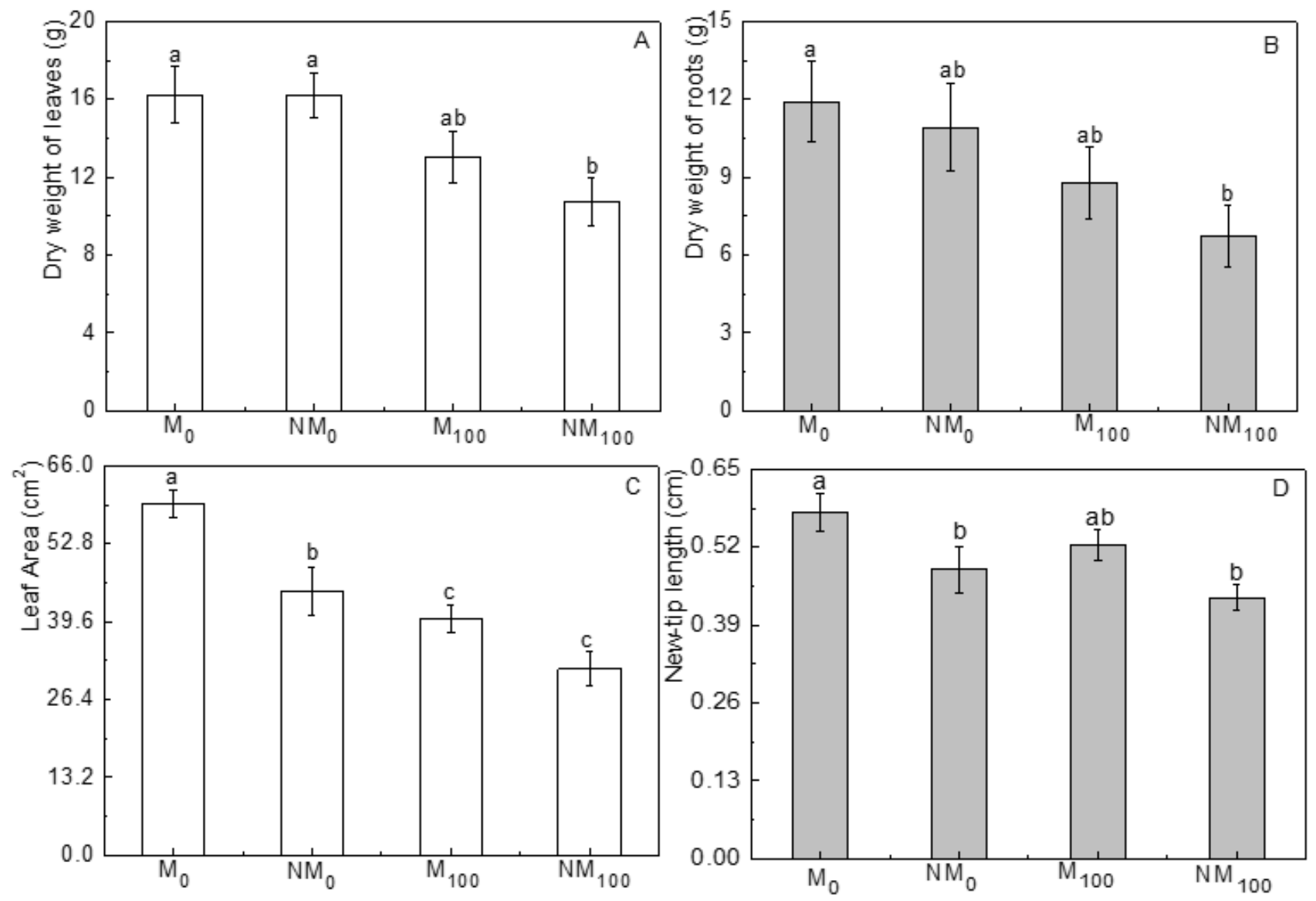

Figure 1

Changes in the biomass (dry weight) of leaves (A) and roots (B), leaf area (C), and length of the new tip (D) in Neva irrigated with or without magnetized water following exposure to 0 or $100 \mu \mathrm{mol} \cdot \mathrm{L}-1$ cadmium stress. Values are the means \pm SE of at least three replicates. Different lowercase letters indicate significant differences among the four treatments at the 0.05 level.
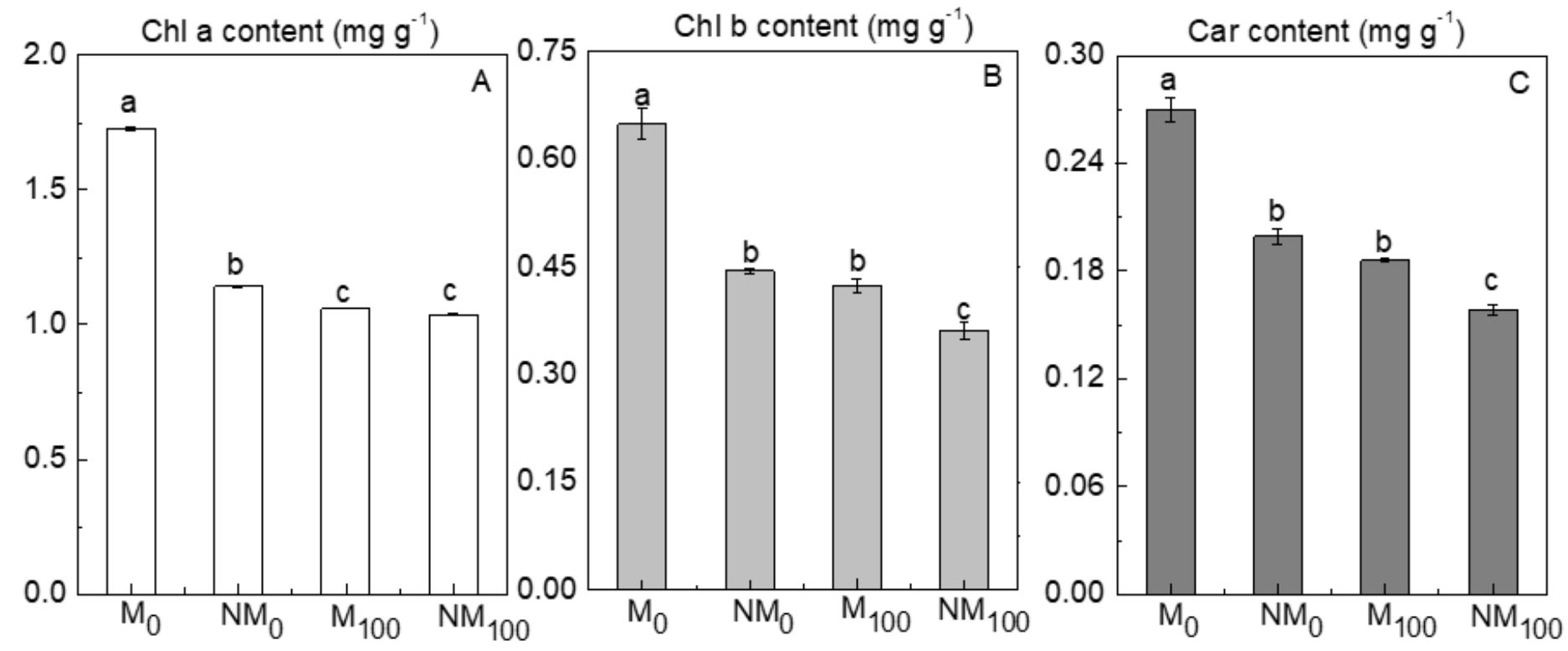

Figure 2 
Changes in the contents of chlorophyll a (Chl a, A), chlorophyll b (Chl b, B), and carotenoids (Car, C) in leaves of Neva irrigated with or without magnetized water following exposure to 0 or $100 \mu \mathrm{mol} \cdot \mathrm{L}-1$ cadmium stress. Values are the means \pm $\mathrm{SE}$ of at least three replicates. Different lowercase letters indicate significant differences among the four treatments at the 0.05 level.
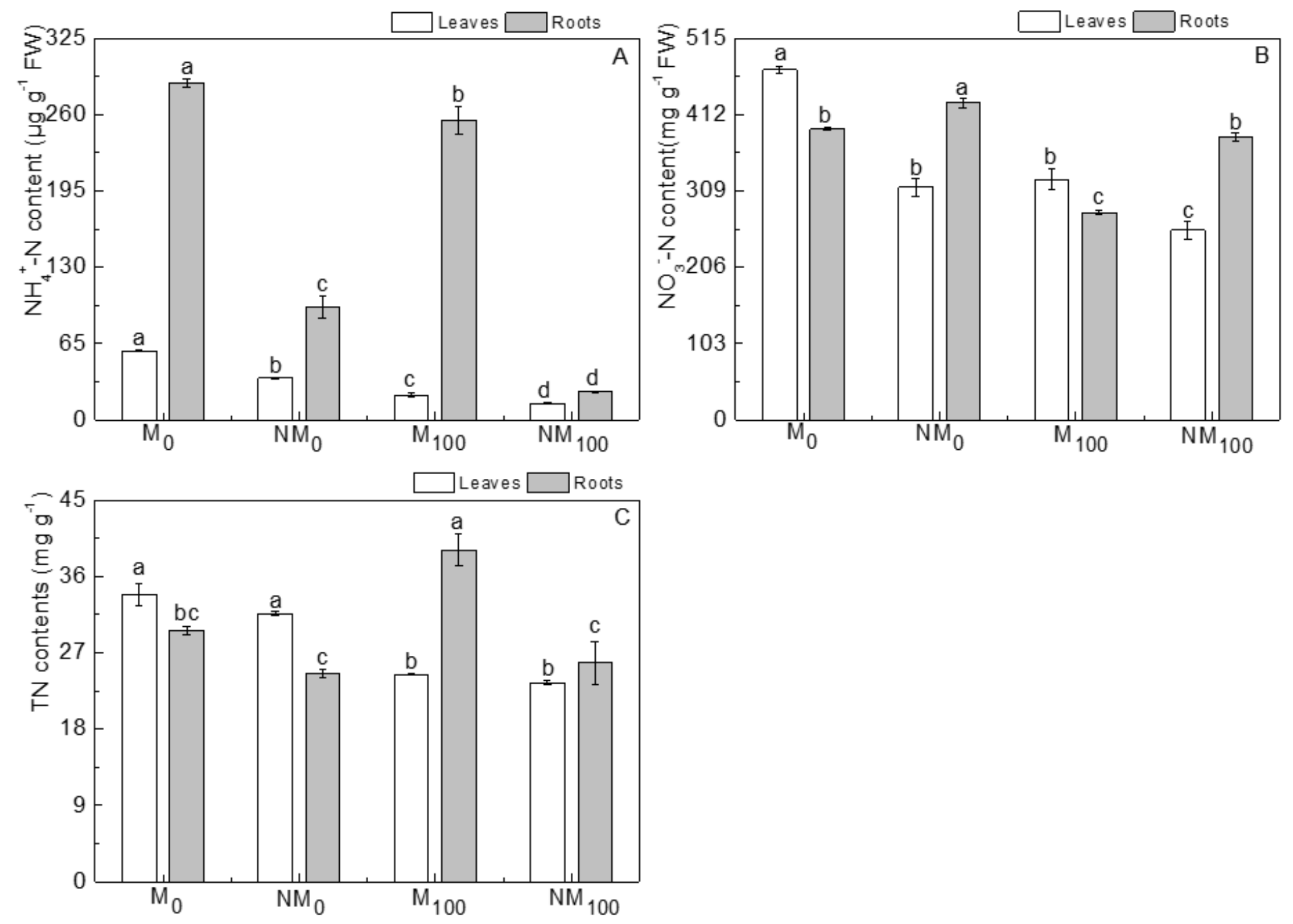

\section{Figure 3}

Changes in the contents of ammonium nitrogen (NH4+-N, A), nitrate nitrogen (NO3-N, B), and total nitrogen (TN, C) in leaves and roots of Neva irrigated with or without magnetized water following exposure to 0 or $100 \mu \mathrm{mol} \cdot \mathrm{L}-1$ cadmium stress.

Values are the means \pm SE of at least three replicates. Different lowercase letters indicate significant differences among the four treatments at the 0.05 level in leaves and roots. 

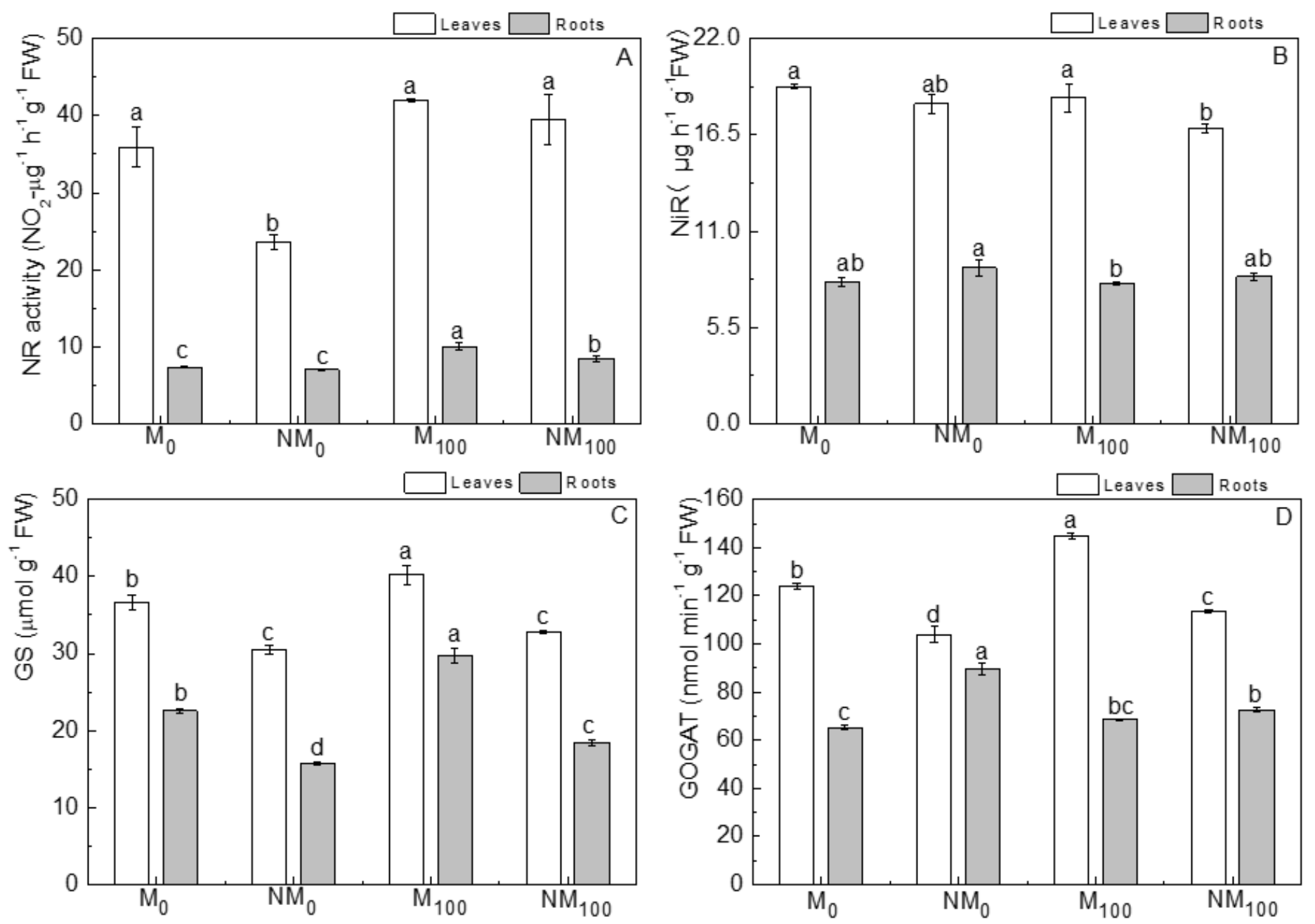

Figure 4

Changes in the activities of nitrate reductase (NR, A), nitrite reductase (NiR, B), glutamine synthetase (GS, C), and glutamate synthase (GOGAT, D) in leaves and roots of Neva irrigated with or without magnetized water following exposure to 0 or 100 $\mu \mathrm{mol} \cdot \mathrm{L}-1 \mathrm{cadmium}$ stress. Values are the means $\pm \mathrm{SE}$ of at least three replicates. Different lowercase letters indicate significant differences among the four treatments at the 0.05 level in leaves and roots. 

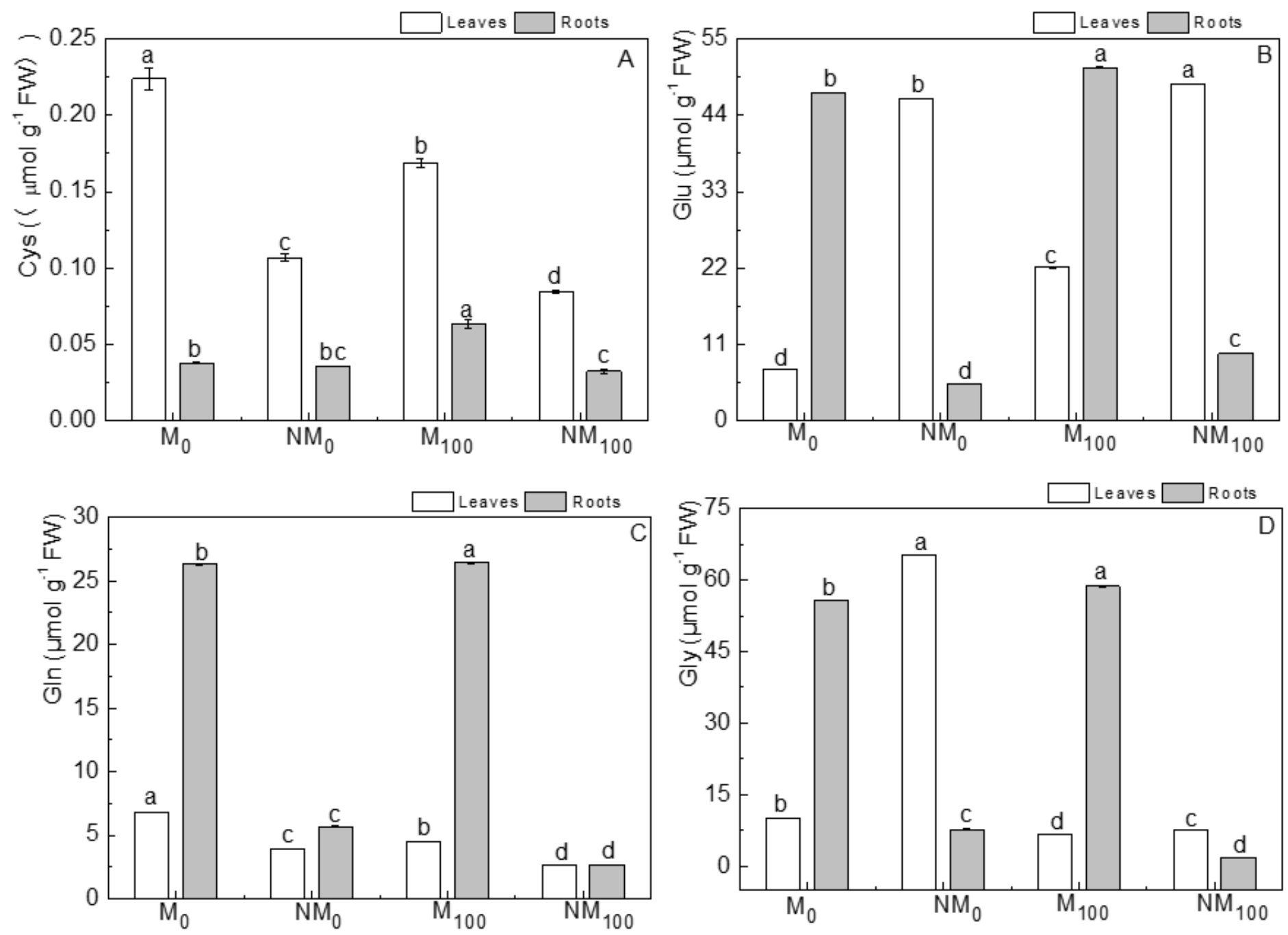

Figure 5

Contents of cysteine (Cys, A), glutamic acid (Glu, B), glutamine (Gln, C), and glycine (Gly, D) in leaves and roots of Neva irrigated with or without magnetized water following exposure to 0 or $100 \mu \mathrm{mol} \cdot \mathrm{L}-1$ cadmium stress. Values are the means \pm SE of at least three replicates. Different lowercase letters indicate significant differences among the four treatments at the 0.05 level in leaves and roots. 

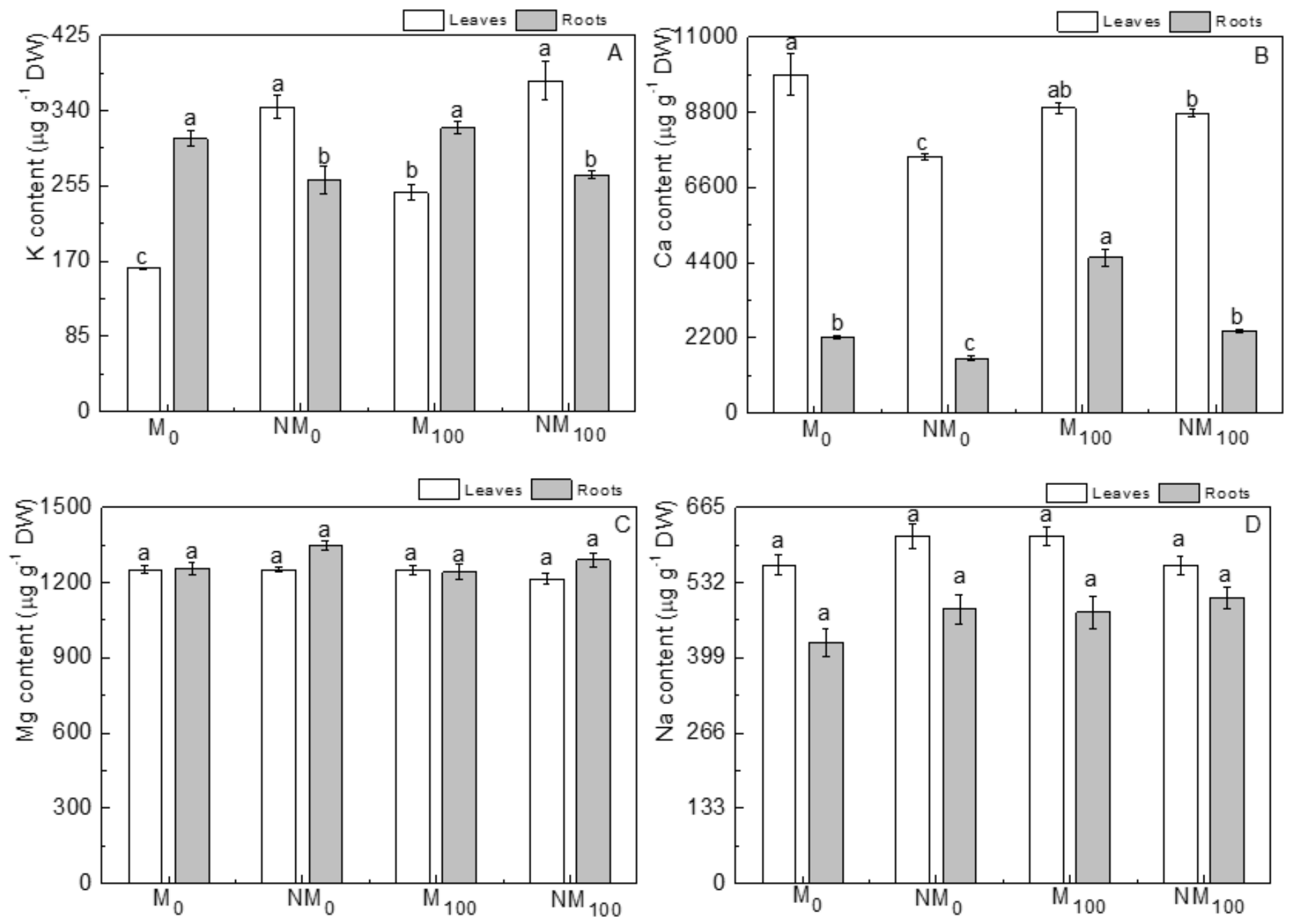

Figure 6

Changes in the contents of potassium $(K, A)$, calcium $(\mathrm{Ca}, \mathrm{B})$, magnesium $(\mathrm{Mg}, \mathrm{C})$, and sodium $(\mathrm{Na}, \mathrm{D})$ in leaves and roots of Neva irrigated with or without magnetized water following exposure to 0 or $100 \mu \mathrm{mol} \cdot \mathrm{L}-1$ cadmium stress. Values are the means \pm SE of at least three replicates. Different lowercase letters indicate significant differences among the four treatments at the 0.05 level in leaves and roots. 

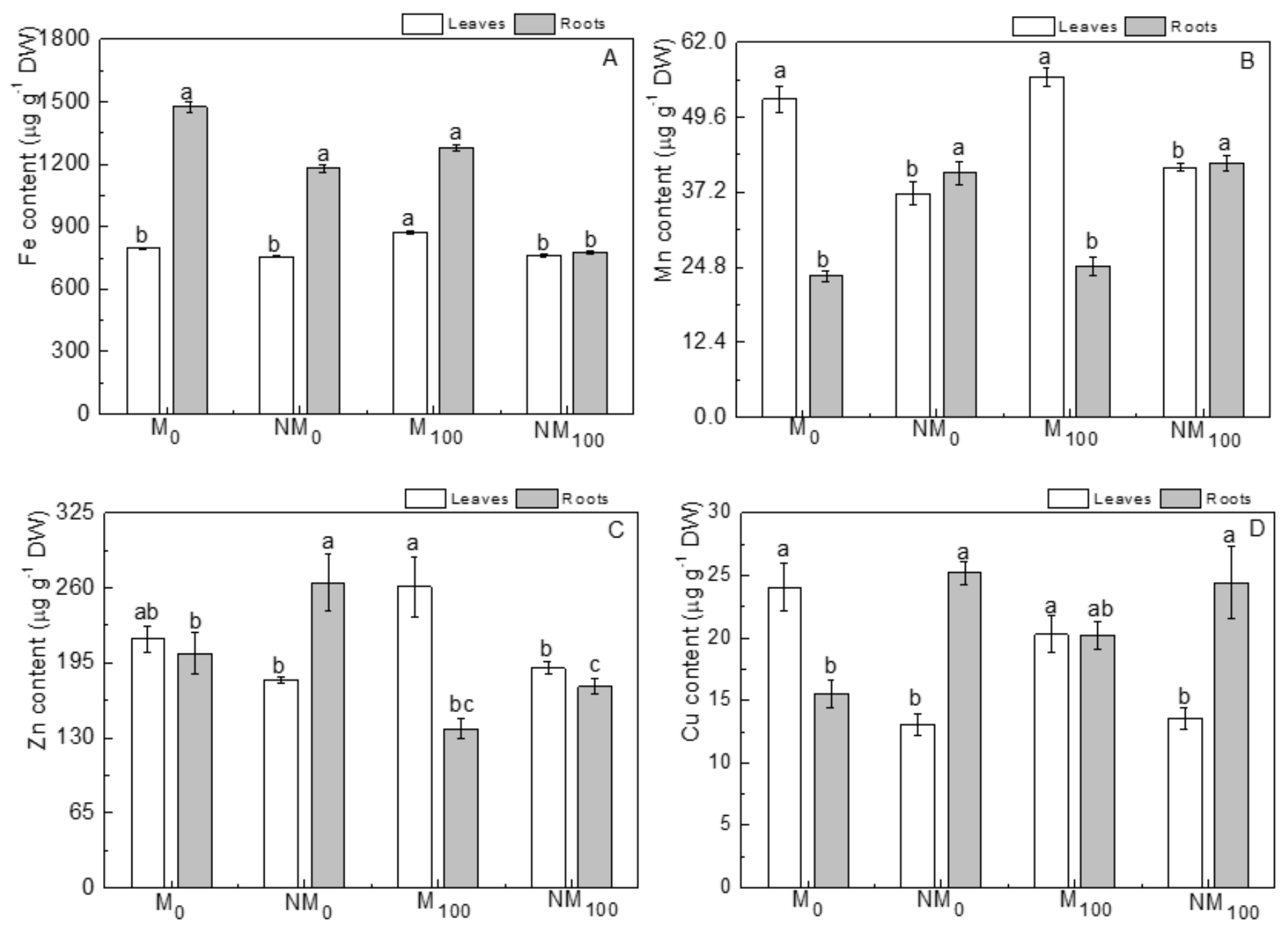

Figure 7

Changes in the contents of iron (Fe, A), manganese ( $\mathrm{Mn}, \mathrm{B})$, zinc ( $\mathrm{Zn}, \mathrm{C})$, and copper (Cu, D) in leaves and roots of Neva irrigated with or without magnetized water following exposure to 0 or $100 \mu \mathrm{mol} \cdot \mathrm{L}-1$ cadmium stress. Values are the means \pm SE of at least three replicates. Different lowercase letters indicate significant differences among the four treatments at the 0.05 level in leaves and roots.

\section{Supplementary Files}

This is a list of supplementary files associated with this preprint. Click to download.

- Supplements.docx 